\title{
An analysis and interpretation of the signals in gamma-absorption measurements of liquid-gas intermittent flow
}

\author{
Marcin Zych ${ }^{1}$ D
}

Received: 26 May 2018 / Accepted: 15 October 2018 / Published online: 22 October 2018

(c) The Author(s) 2018

\begin{abstract}
The intermittent flow (slug and plug type) of liquid-gas mixtures in a horizontal pipeline measured by the specific radiometric apparatus is presented. The measurement system consists of two sources of Am-241 gamma radiation and two scintillation probes. An analysis of the signals measured by the radiometric equipment is performed in the domain of time and of frequency. Recognised signal parameters are directly referred to physical quantities associated with a liquid-gas flow. The employed methodology enables determination of gas-phase flow velocity and estimation of the average depth and length of bubble gas structures. In the paper, the processing and interpretation results of the selected experiment are presented to show the in-depth description of gas structures and the type of flows recognition.
\end{abstract}

Keywords Liquid-gas flow $\cdot$ Slug flow $\cdot$ Plug flow $\cdot$ Flow structures $\cdot$ Gamma absorption $\cdot$ Signals analysis

\section{Introduction}

Multiphase flows, including two-phase liquid-gas and liquid-solid particle flows, are very common in industrial processes, for example in the production of crude oil, which is accompanied by natural gas extraction, in the petrochemical industry in the processing of crude oil.

Two-phase liquid-gas mixtures, depending on the angle of inclination and the diameter of the pipeline, the velocity of the transport or the relationship between the content of both phases may produce various flow structures. Therefore, it is difficult to describe and to measure such a flow. This necessitates the development of measurement technology on the basis of parameters such as flow velocity or the coefficients of the contribution of the particular phases. The recognition of the type of flow (Roshani et al. 2017b; Hanus et al. 2018) and the imaging of a multiphase flow (Mosorov 2008) also becomes crucial. The information which is provided owing to experiments enables progress as far as better mathematical modelling of such flows is concerned (Jaszczur and Portela 2008; Gulhane and Mahulikar 2009).

Marcin Zych

zych@geol.agh.edu.pl

1 Faculty of Geology, Geophysics and Environmental Protection, AGH University of Science and Technology, 30 Mickiewicz Av., 30-059 Kraków, Poland
The advanced measurement technologies of multiphase flows include tomographic methods: electrical ones (capacitance, resistance, impedance), which use the absorption of $\mathrm{X}$-rays and gamma rays, nuclear magnetic resonance (NMR) and optical ones (e.g. PIV-particle image velocimetry) (Mosorov 2006a; Powell 2008; Falcone et al. 2009; Rząsa 2009; Rahim et al. 2012; Xue et al. 2012; Tamburini et al. 2013; Banasiak et al. 2014; de Oliveira et al. 2015; Kanizawa and Ribatski 2016; Ameran et al. 2017; Vlasak et al. 2017). Tomographic methods are also used to establish crucial petrophysical parameters of rocks, such as porosity and permeability (Krakowska and Puskarczyk 2015; Jarzyna et al. 2016; Kundu et al. 2017). Although the technology of tomographic measurements is a familiar phenomenon, research in the development of such methods continues because the measurement systems usually constitute complex multi-sensor systems. As far as environment protection and hydrogeology is concerned, radiotracer methods are applied (Witczak et al. 2009; García et al. 2017; Biswal et al. 2018). The development of the aforementioned measurement methods is also facilitated by the progress in the analysis of signals which uses advanced mathematical methods. The latter are widely used, for example, in geotechnics, environment protection and geophysics (Buttkus 2000; Pietsch et al. 2007; Gołębiowski et al. 2016; Kozłowska et al. 2016; Szabó and Dobróka 2017). 
Considering the fact that a significant part of the liquid-gas flows is transported in pipelines whose diameter is less than $100 \mathrm{~mm}$ (e.g. during the extraction of oil and natural gas in oil rigs), the problem of hydrotransport frequently may be reduced from a description in three or two dimensions to a description in one dimension. Due to this, complex systems intended for tomography may be replaced with simpler and frequently less expensive systems. That is why this article presents the application of a system which consists of two probes with $\mathrm{NaI}(\mathrm{Tl})$ scintillating crystals and two sealed sources of gamma-ray Am-241. The electrical signals which are obtained at the output of the measurement systems were subject to an analysis in the domain of time and of frequency. The properties of signals which were distinguished were related by author to physical quantities in the two-phase liquid-gas flow, such as the length and the depth of gas structures.

\section{The measurement system}

The idea of using the absorption of gamma rays in the measurements of two-phase flows was discussed in a more comprehensive way in the following articles: Chaouki et al.

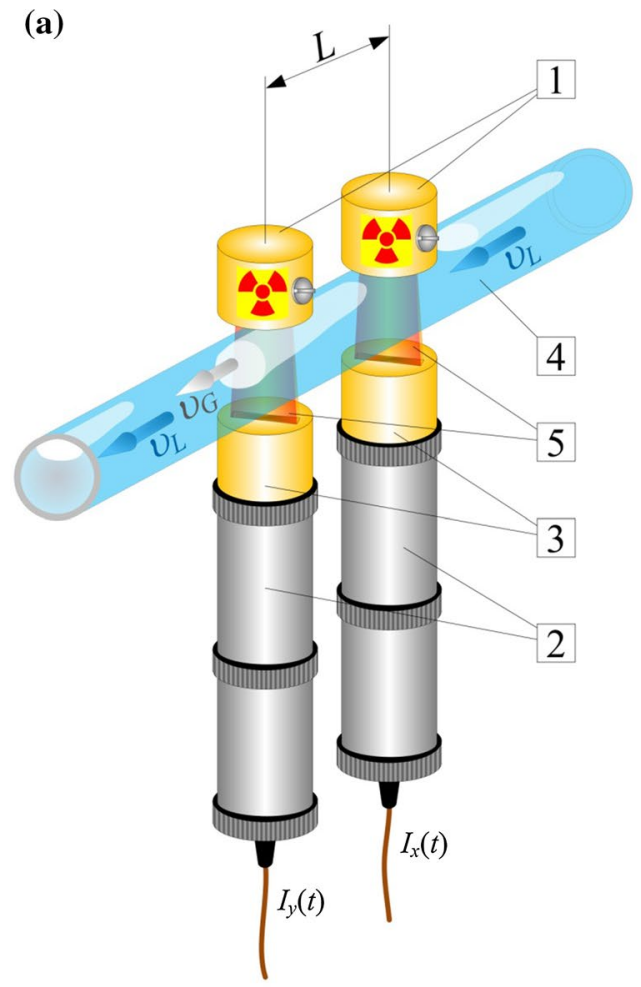

Fig. 1 System intended for the research of two-phase liquid-gas flows by means of the absorption method: a the design of the system: 1-collimators with sources of Am-241, 2-scintillation probes, 3-probe collimators, 4-a pipeline with the flowing mixture, 5-a
(1997), Johansen and Jackson (2004), Heindela et al. (2008), Kumara et al. (2010), Vlasak et al. (2014), Roshani et al. (2017a). The measurement systems which were applied are used above all to establish the contribution of the particular phases and to identify a flow structure. Therefore, the gamma-ray detectors which were used were a part of spectrometric tracks (Knoll 2000).

The research station is located in the AGH University of Science and Technology in Kraków.

Using the described measurement system, a number of experiments were carried out aimed at the development of the gamma-ray absorption method to determine the transport time delay and velocity of the dispersed phase, and recognition of flow types. The results of the experiments and the research station were detailed in the following works: Zych et al. (2014, 2015, 2016, 2018), Hanus (2015), Hanus et al. (2018).

The main part of the radiometric measurement system is presented in Fig. 1a, b. It consists of two scintillating detectors (2) with $\mathrm{NaI}(\mathrm{Tl}) 2^{\prime \prime} \times 2$ " crystals on which lead collimators are superimposed (3) whose purpose is to reduce scattered radiation. Sealed sources of gamma radiation are placed in lead collimators (1) with a slot, whose shape enables the appropriate shape of the radiation beams (5). Due to

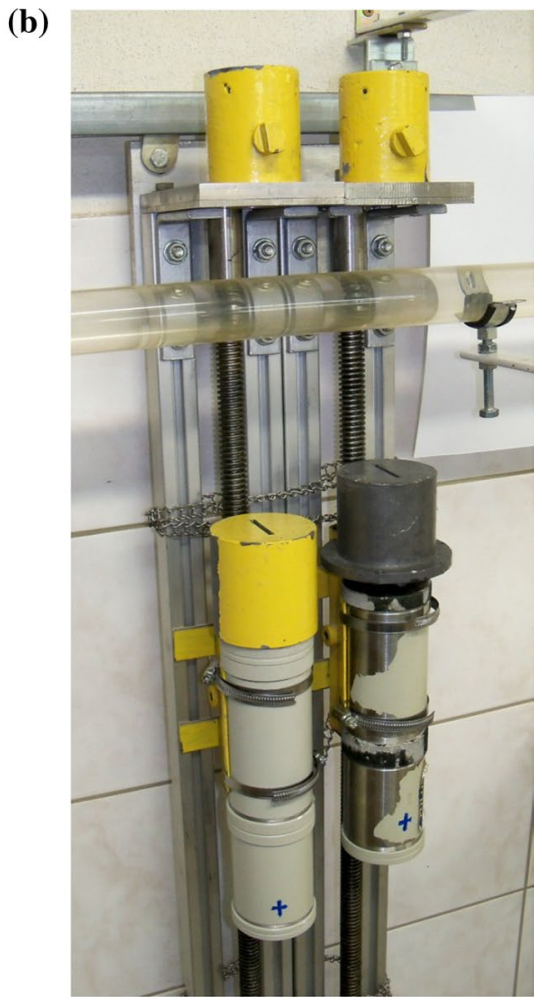

beam of gamma rays, $L$ - the distance between probes, $v_{L}$ - the average velocity of the flow of a liquid, $v_{\mathrm{G}}$-the average velocity of the flow of a gas, $I_{x}(t), I_{y}(t)$-signals from probes, $\mathbf{b}$ a photograph of the absorption apparatus (Zych et al. 2014; Hanus 2015) 

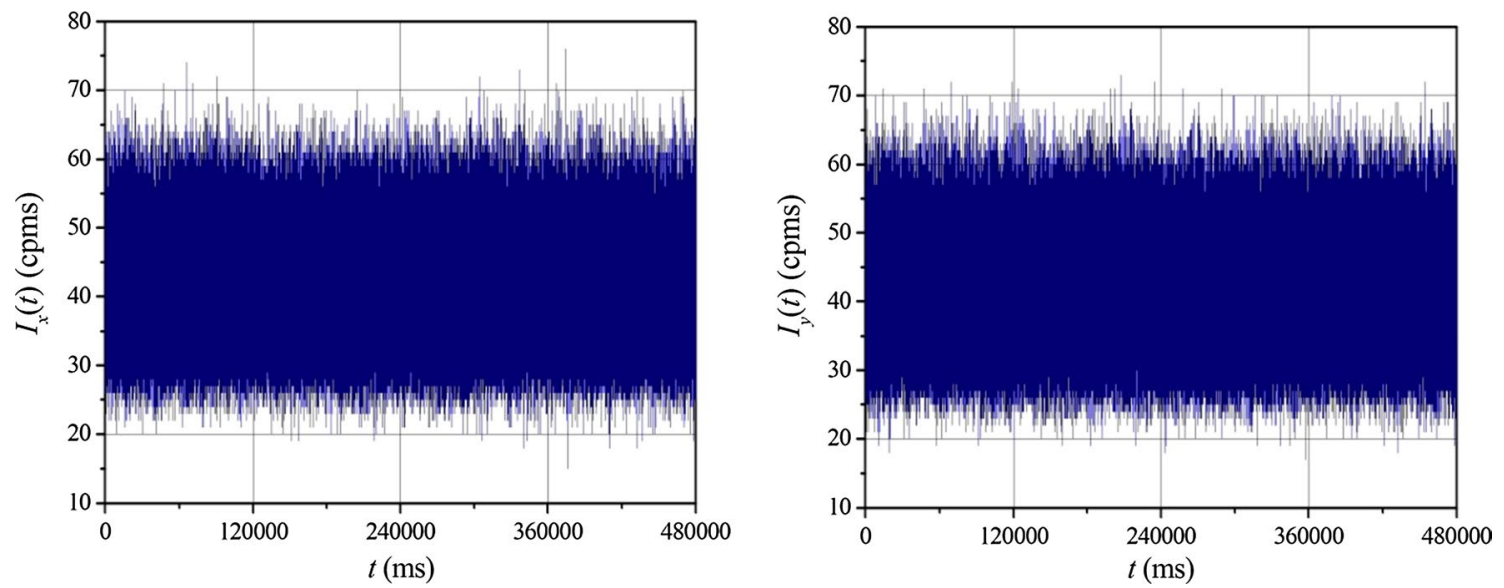

Fig. 2 Signals registered in the LIW0004 experiment for the intermittent flow

Table 1 Basic characteristics of analysed flows: $v_{\mathrm{L}}$-average velocity of water, $R e$ - Reynolds number, $\mathrm{Fr}$-Froude number, $\alpha$-average void fraction of gas phase, $q_{\mathrm{G}}$-air expense

\begin{tabular}{lllllll}
\hline Run & $v_{\mathrm{L}}(\mathrm{m} / \mathrm{s})$ & $\alpha(-)$ & $\operatorname{Re}(-)$ & $F r^{2}(-)$ & $q_{\mathrm{G}}(1 / \mathrm{min})$ & Type of flow \\
\hline LIW0005 & 1.66 & 0.434 & $1.9 \times 10^{4}$ & 1.01 & 18 & Slug \\
LIW0003 & 2.16 & 0.312 & $2.7 \times 10^{4}$ & 1.14 & & Plug \\
LIW0004 & 2.92 & 0.266 & $3.7 \times 10^{4}$ & 5.89 & & \\
LIW0002 & 3.28 & 0.240 & $4.3 \times 10^{4}$ & 7.43 & & \\
\hline
\end{tabular}

the low density of the water-air mixture, in order to ensure appropriate sensitivity for the method which is presented, one applied linear sources of Am-241 whose radiation energy is $59.54 \mathrm{keV}$ and whose activity is $100 \mathrm{mCi}$. The mixture which was studied is transported in a horizontal pipeline (4), made of a Plexiglas pipe whose internal diameter is $30 \mathrm{~mm}$ and whose wall has the thickness of $5 \mathrm{~mm}$ and whose length is $4.5 \mathrm{~m}$. The flow of the mixture is prompted by a rotary pump whose rotational speed may be regulated. This enables the maintenance of an average flow velocity $v_{\mathrm{L}}$ for a liquid phase from 0.15 to $3.6 \mathrm{~m} / \mathrm{s}$. The two-phase liquid-gas flow is obtained by regulation of the supply of air from the compressor to the installation before the measurement section. The airflow of up to $18 \mathrm{l} / \mathrm{min}$ enables the following flow structures to be obtained: the stratified-wavy, the intermittent (for which one also distinguishes the slug and the plug flows) and the bubble flow. Moreover, the measurement station was equipped with an ultrasound flow meter used to measure the velocity of the water and with a camera used to conduct optical measurements.

The detectors operated in the meter mode, registering the intensity (which varied in the course of time) of the radiation which passed through the flowing mixture. The probes were connected by a measuring card, which was a part of the data acquisition system. The measuring card and the dedicated software enable the sampling of the signal with a minimal period, i.e. $\Delta t=1 \mathrm{~ms}$. An example register of the signals which was provided by the measurement system
Table 2 Average values of the velocity of gas phase $v_{\mathrm{G}}$ and the values of the measurement uncertainty $u_{\mathrm{c}}\left(v_{\mathrm{G}}\right)$ for the flow of gas in the measurements which were analysed

\begin{tabular}{lll}
\hline Run & $v_{\mathrm{G}}(\mathrm{m} / \mathrm{s})$ & $u_{\mathrm{c}}\left(v_{\mathrm{G}}\right)(\mathrm{m} / \mathrm{s})$ \\
\hline LIW0005 & 1.325 & 0.053 \\
LIW0003 & 1.792 & 0.055 \\
LIW0004 & 2.059 & 0.054 \\
LIW0002 & 2.304 & 0.062 \\
\hline
\end{tabular}

that was used for the LIW0004 measurement is presented in Fig. 2. Experiment LIW0004 was made with a pump speed of $1900 \mathrm{r} / \mathrm{min}$ and air flow from the compressor $18 \mathrm{l} / \mathrm{min}$. This allowed, in the measuring section, to obtain an average flow velocity $v_{\mathrm{L}}=2.92 \mathrm{~m} / \mathrm{s}$, while the average air velocity was $v_{\mathrm{G}}=2.059 \mathrm{~m} / \mathrm{s}$ (Tables 1,2 ). The gas structures that formed during the flow were classified as a plug flow. The distinction between the observed flow structures is described in the following chapters.

\section{Characteristics of analysed structures of a liquid-gas flow}

The present article analyses two types of intermittent flows which are produced at various velocities of water and the contribution of water and air in the mixture (Salgado et al. 
2010; Zhao et al. 2013; de Oliveira et al. 2015; Kanizawa and Ribatski 2016; Roshani et al. 2017a).

Figure 3 shows the distribution of flow structures for LIW0004 measurement (plug flow). This distribution is similar for the other analysed experiments. The intermittent flow can be distinguished by a large gas structure consisting of a large bubble with a free surface at the gas-liquid interface and a small gaseous structure (consisting of small bubbles).

Figure $4 a, b$ presents the largest gas structures for the flow of the slug type (runs LIW0005 and LIW0003). Due to the length of such a bubble, which may reach even up to circa $2 \mathrm{~m}$, selected fragments are indicated. The flow of the slug type is characterised by long, large bubbles filling almost the entire cross section of the pipeline. Between these bubbles are smaller gas structures. However, Fig. 4c, d illustrates the structures which are peculiar to the flow of the plug type (LIW0004 and LIW0002 runs).
These bubbles are considerably shorter, which to a lesser extent fill the cross section of the pipeline (see the values of void fraction $\alpha$-Table 1). In a plug flow, there are a much larger number of small bubbles in the gas structure between the large bubbles.

The basic quantities which describe the analysed flows are presented in Table 1.

The following relations were assumed in reference to the calculations:

- Reynolds number for water phase:

$$
R e=\frac{v_{\mathrm{L}} \cdot D_{\mathrm{ch}} \cdot \rho}{\eta}
$$

- Square of Froude number (Morgado et al. 2016; García et al. 2017):

$$
F r^{2}=\frac{\left(v_{\mathrm{L}}-v_{\mathrm{G}}\right)^{2}}{a_{\mathrm{g}} \cdot D_{\mathrm{ch}}}
$$

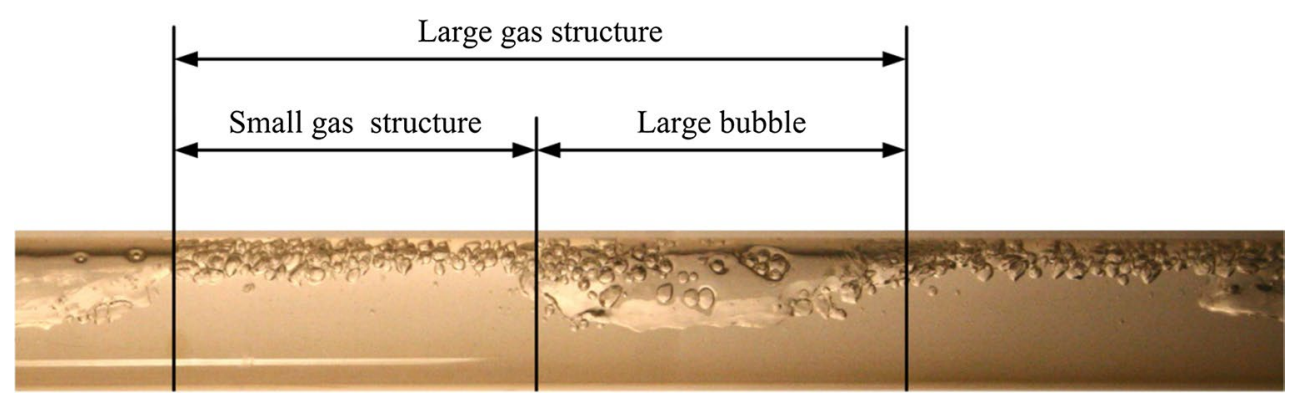

Fig. 3 Distribution of gas structures in the intermittent flow, on the example of the LIW0004 experiment

(a)

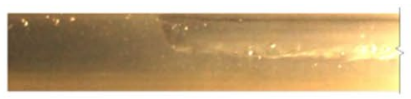

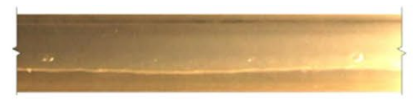
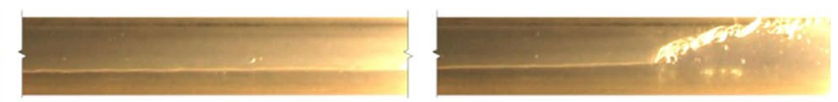

(b)
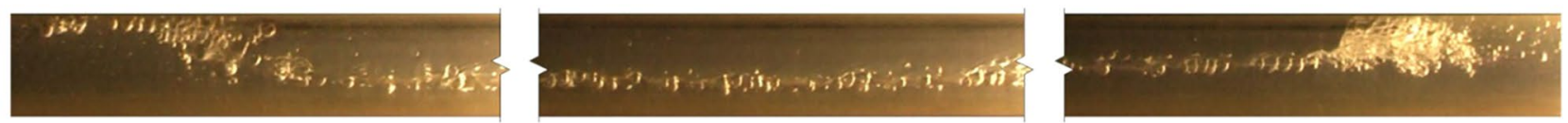

(c)

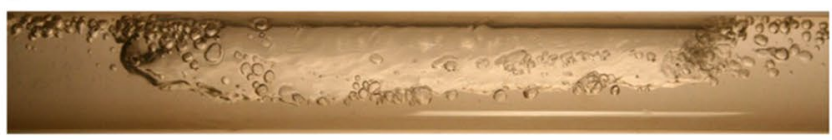

(d)

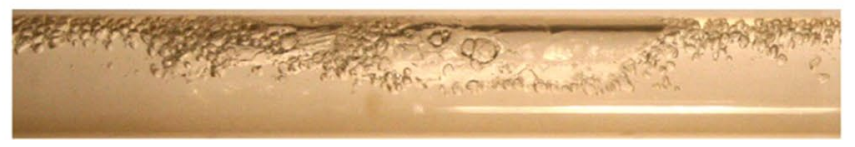

Fig. 4 Characteristic gas structures in intermittent flows: the slug flow type-a LIW0005, b LIW0003 and the plug flow type-c LIW0004, d LIW0002 
- Characteristic dimension for liquid phase:

$$
D_{\mathrm{ch}}=r \sqrt{1-\alpha}
$$

where $\eta$ is the dynamic viscosity ( $\mathrm{Pa} \mathrm{s}), a_{\mathrm{g}}$ the gravity acceleration $\left(\mathrm{m} / \mathrm{s}^{2}\right), \alpha$ the average void fraction $(-), r$ the radius of pipeline $(\mathrm{m})$ and $\rho$ the density of liquid $\left(\mathrm{kg} / \mathrm{m}^{3}\right)$.

\section{Methodology of signal analysis}

\section{Determining the average velocity of gas phase}

In reference to the measurement system presented in Fig. 1, the establishment of the average velocity of the flow of the gas phase (which in this case is a dispersed phase) is performed by determining the time of the transport delay $\tau_{0}$ between two signals from probes placed at a distance $L$. Then, the average velocity of the flow of the gas phase may be expressed by the following relationship:

$v_{\mathrm{G}}=\frac{L}{\tau_{0}}$

Various statistical methods are used to determine $\tau_{0}$. The most popular ones include the cross-correlation function (CCF) and methods based on a modification of CCF, such as differential and complex functions, CCF with Hilbert's transform, conditional averaging, deconvolution and the phase method (Hanus 2003; Mosorov 2006b; Sommerlatt and Andruszkiewicz 2008; Hanus 2009; Kowalczyk et al. 2011; Hanus et al. 2014; Zych et al. 2015; Zeng et al. 2016; Arkani et al. 2017). The cross-correlation function may be applied to signals whose relation of the signal to noise is unfavourable. The present work uses the cross-correlation function which is described by the equation for discreet signals (Beck and Plaskowski 1987):

$R_{x y}(\tau)=\frac{1}{N} \sum_{n=0}^{N-1} x(n) \cdot y(n+\tau)$

where $x(n)$ and $y(n)$ constitute digital realisation of $I_{x}(t)$ and $I_{y}(t)$ signals, $n$ is linked with the time of the measurement and of sampling by the $n=t / \Delta t$ relationship and $N$ is the number of the discreet values of signals.

The argument of the maximum course of CCF is assumed to be the most likely duration of the transport delay (estimator) $\tau_{0}$ :

$\hat{\tau}_{0}=\arg \left\{\max R_{x y}(\tau)\right\}=\arg \left\{R_{x y}\left(\tau_{0}\right)\right\}$
The fragment of CCF, which is subject to the analysis, along with the determined maximum and the standard deviation $\sigma$, is presented in Fig. 5 for the run LIW0004 (Zych et al. 2017).

The complex uncertainty of the measurement of the velocity of the gas phase was determined on the basis of the law of the propagation of uncertainty, according to (Guide 1995):

$u_{\mathrm{c}}\left(v_{\mathrm{G}}\right)=\sqrt{\left(\frac{1}{\hat{\tau}_{0}} u_{\mathrm{B}}(L)\right)^{2}+\left(\frac{L}{\left(\hat{\tau}_{0}\right)^{2}} u_{\mathrm{A}}\left(\hat{\tau}_{0}\right)\right)^{2}}$

whereas the uncertainty of the time of the transport delay was determined on the basis of the relationship:

$u_{\mathrm{A}}\left(\hat{\tau}_{0}\right)=\frac{\sigma}{\sqrt{m}}$

where $m$ is the number of points which belong to the CCF graph, which is shaded in Fig. 5, whereas the value $u_{\mathrm{B}}(L)$ designates the precision of the measurement with the help of a vernier calliper gauge, equal to $0.1 \mathrm{~mm}$.

The determination/evaluation of the velocity of the flow of the gas phase is crucial for a further analysis and interpretation of the measurements which are presented. It is also one of the basic parameters which characterise the two-phase liquid-gas-type flow.

Table 2 presents the average velocities of the flow of gas $v_{\mathrm{G}}$ along with the uncertainties of the measurement $u_{\mathrm{c}}\left(v_{\mathrm{G}}\right)$ which were calculated for the analysed measurements.

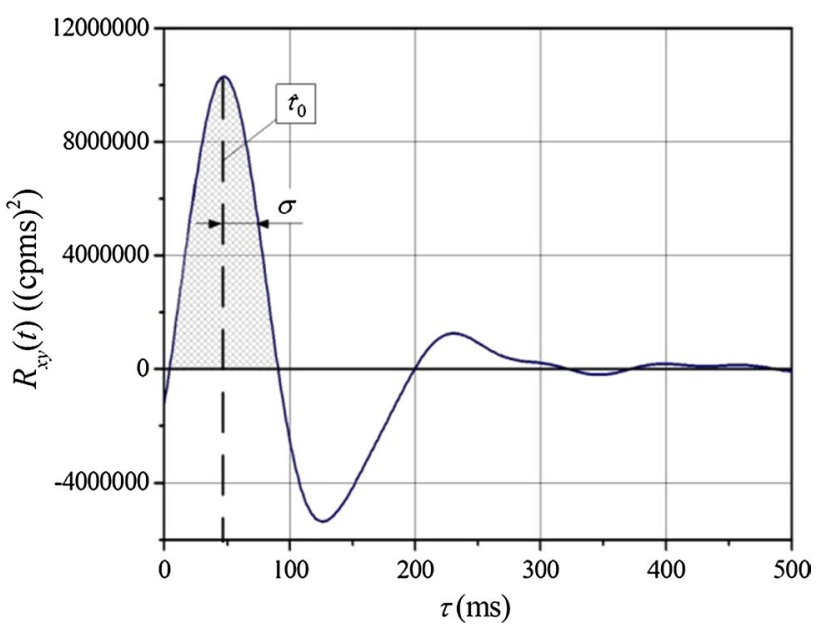

Fig. 5 Cross-correlation function for the LIW0004 run: $\hat{\tau}_{0}$ - estimator of the duration of the transport delay, $\sigma$ - standard deviation of the distribution 


\section{Determining the depth of gas structures}

The radiometric measurement system which is presented in the "The measurement system" section may also be utilised in a classical way to determine the density of the mixture or the void fraction $\alpha$ for the gas phase (Arvoh et al. 2012; Zhao et al. 2013; Roshani and Nazemi 2017). This requires prior experimental calibration of the apparatus due to which one obtains a relationship which links the number of the combined calculations $I$ of gamma quanta registered by the scintillation probe with $\alpha$. A detailed description of the process of calibration and the utilisation of the relationship which was obtained is presented in the following article: Zych et al. (2016).

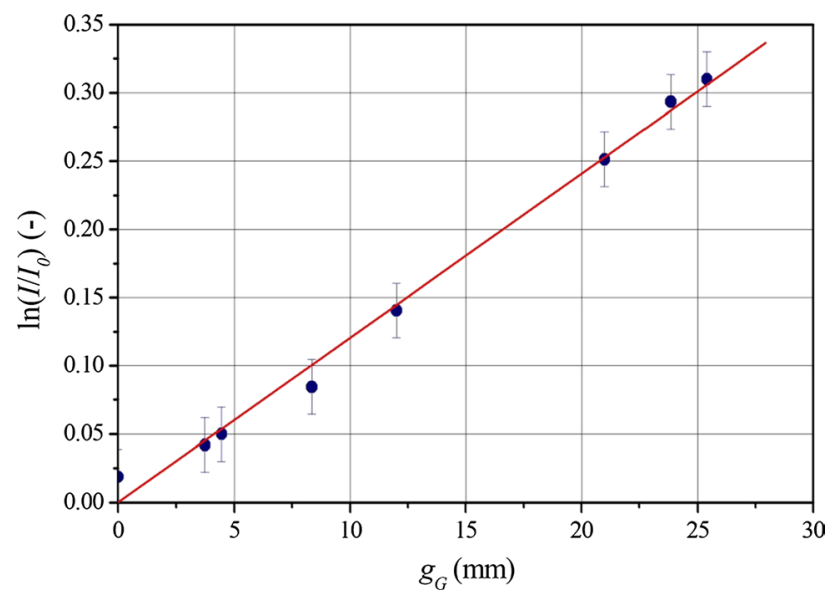

Fig. 6 Relationship between the intensity of radiation $I$ and the depth of the gas $-g_{\mathrm{G}}$
As a result of the calibration, relationship was determined by Eq. 9, where $g_{\mathrm{G}}$ is the depth of the structure of the transported gas. This relationship is presented in Fig. 5. It is described by the Lambert-Beer law:

$\ln \left(I / I_{0}\right)=\mu \cdot g_{\mathrm{G}}$

where $\mu$ is the coefficient of the attenuation of radiation in the mixture, $I$ the intensity of gamma radiation after the scanning of the mixture and $I_{0}$ the intensity of radiation registered by the probe for a pipeline which is filled completely with water.

Based on Eq. 9, one may evaluate the average depth of the bubbles (Zych et al. 2018).

Due to the adjustment of the straight line to the measurement points indicated in Fig. 6, one obtained the value of the attenuation coefficient of radiation $-\mu=(0.01204 \pm 0.0$ 0042) $\mathrm{mm}^{-1}$.

The idea of the measurement of the depth and the length of the gas structures in the time domain is presented in Fig. 7. In order to illustrate the variability of the signal for the run LIW0003 better, the signal was subject to prior filtration. Due to this fact, the intensity of gamma radiation was designated $I_{y} \times(t)$ on the vertical axis. However, for the purposes of the calculations one uses data which were not subject to filtration. Figure 7 presents the length of a large bubble $-l_{\mathrm{b}}$, which corresponds to the temporal duration of the signal $t_{\mathrm{b}}$. The parameter $t_{1}$ is the duration of a large gas structure, which consists of a large bubble and gas structures located between large bubbles. Due to the fact that one may separate individual gas structures and large bubbles from a duration of a signal for intermittent flows, one may estimate their average depth. Then, one must separate a fragment of a signal with an amplitude $I_{\mathrm{b}}$, which enables
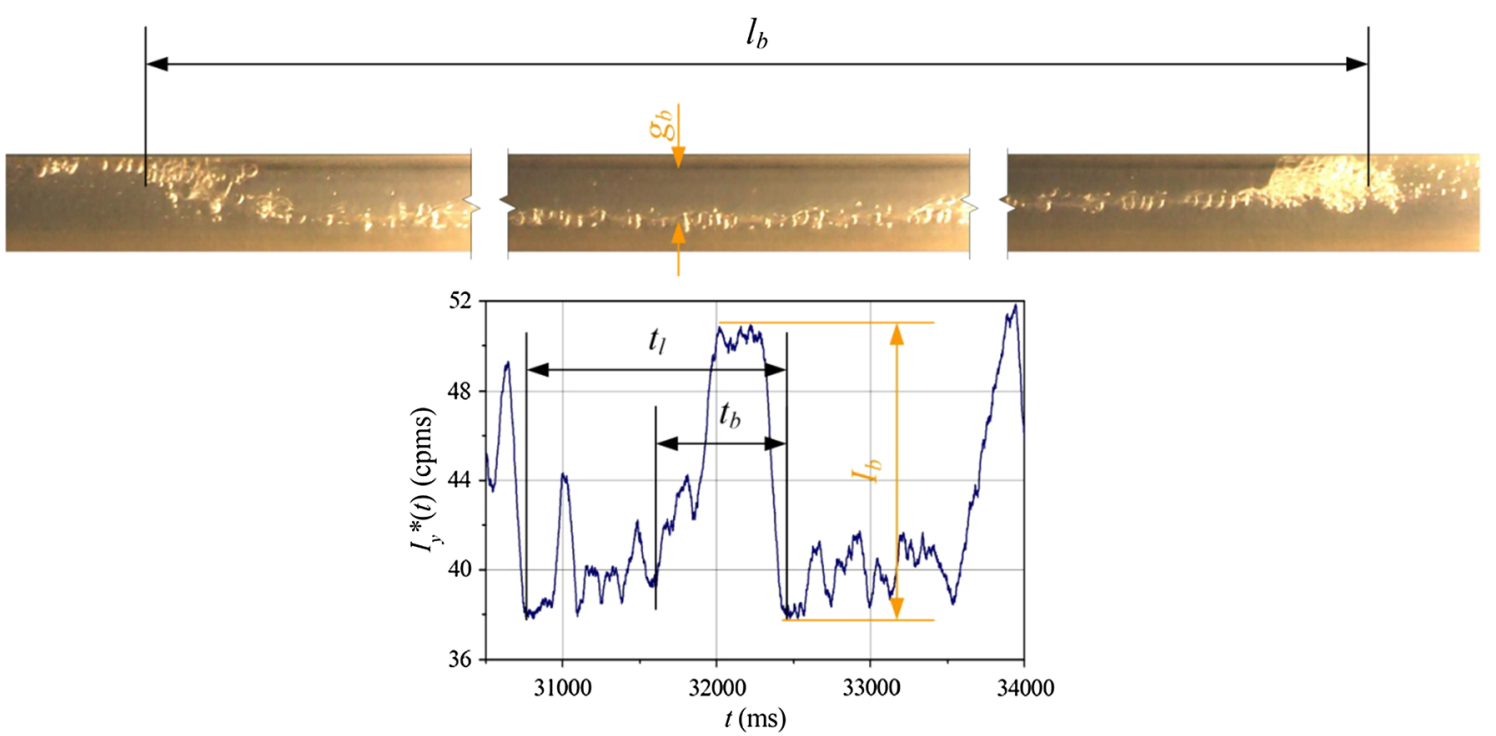

Fig. 7 Idea of the measurement of the depth $g_{\mathrm{b}}$ and the length $l_{\mathrm{b}}$ of large gas bubbles in an intermittent flow (run LIW0003) 
the establishment of an average depth of a large bubble $g_{\mathrm{b}}$ by means of an equation (Eq. 9). This means that in reference to individual structures one assumes an ersatz model of a bubble in a projection on a lateral plane contiguous with the pipeline, as a rectangle whose height is $g_{\mathrm{b}}$. However, as far as the establishment of an average depth $g_{\mathrm{G}}$ of a gas bubble in a pipeline for the entire measurement is concerned, one assumed an equivalent model of the structure, as in the case of a stratified flow.

The precision of the establishment of the average depth of a gas structure was estimated on the basis of the law of the propagation of uncertainty from the following relationship (Eq. 9):

$u_{\mathrm{c}}\left(g_{\mathrm{G}}\right)=\sqrt{\left(\frac{1}{\mu \cdot I} u_{\mathrm{A}}(I)\right)^{2}+\left(\frac{1}{\mu \cdot I_{0}} u_{\mathrm{A}}\left(I_{0}\right)\right)^{2}+\left(\frac{\ln \left(I / I_{0}\right)}{\mu^{2}} u_{\mathrm{A}}(\mu)\right)^{2}}$

Due to the fact that the process of radioactive decay is a stochastic process, one assumed the following equation in reference to the uncertainty of the establishment of the intensity of radiation $I$ :

$u_{\mathrm{A}}(I)=\frac{\sqrt{I}}{n}$
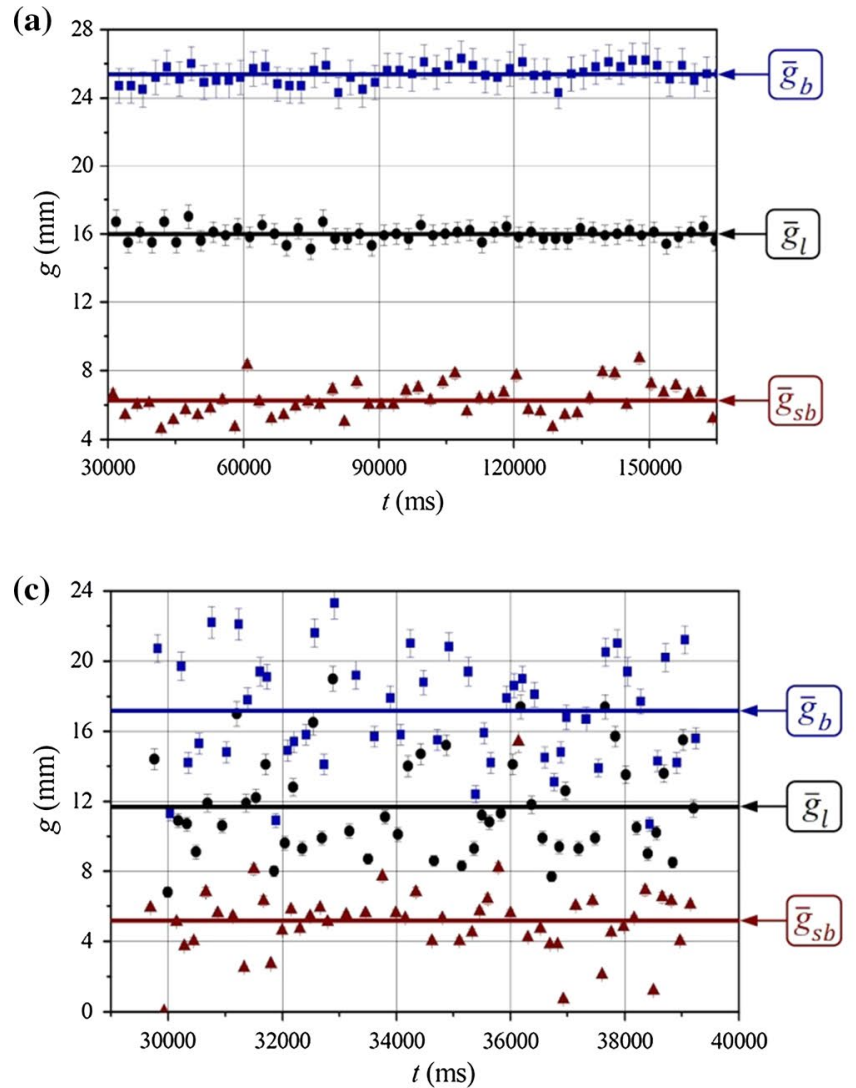

where $n$ is the number of data.

As far as the measurements which are presented are concerned, one performed analyses in the domain of time for further 50 fragments of the signal. The part of the signal which was analysed was selected in such a way as to be representative for the whole measurement. As a result of the calculations which were performed, one obtained average values of the depths of large gas structures $g_{1}$, of large gas bubbles $g_{\mathrm{b}}$ and of small gas structures $g_{\mathrm{sb}}$, which arise between large bubbles. The distribution of the values of the depth of the structures is presented in Fig. 8a, b for the flows of the slug type and Fig. $8 \mathrm{c}, \mathrm{d}$, for the flows of the plug type. The black circles represent the depths of gas structures, the blue squares represent the depths of large gas bubbles, whereas the triangles represent the depths of small gas structures. Continuous lines designated $\bar{g}_{l}, \bar{g}_{\mathrm{b}}, \bar{g}_{\mathrm{sb}}$ represent the average values for all 50 fragments of the signals which were analysed, respectively. Table 3 presents the average values of the depths of the structures and indicates the uncertainty of the measurements and the respective standard deviation $-\sigma_{\mathrm{l}}, \sigma_{\mathrm{b}}, \sigma_{\mathrm{sb}}$.

An analysis of the graphs presented in Fig. 8 and the values of standard deviation, presented in Table 3 , indicate that the flows of the slug type are characterised by a lesser extent of
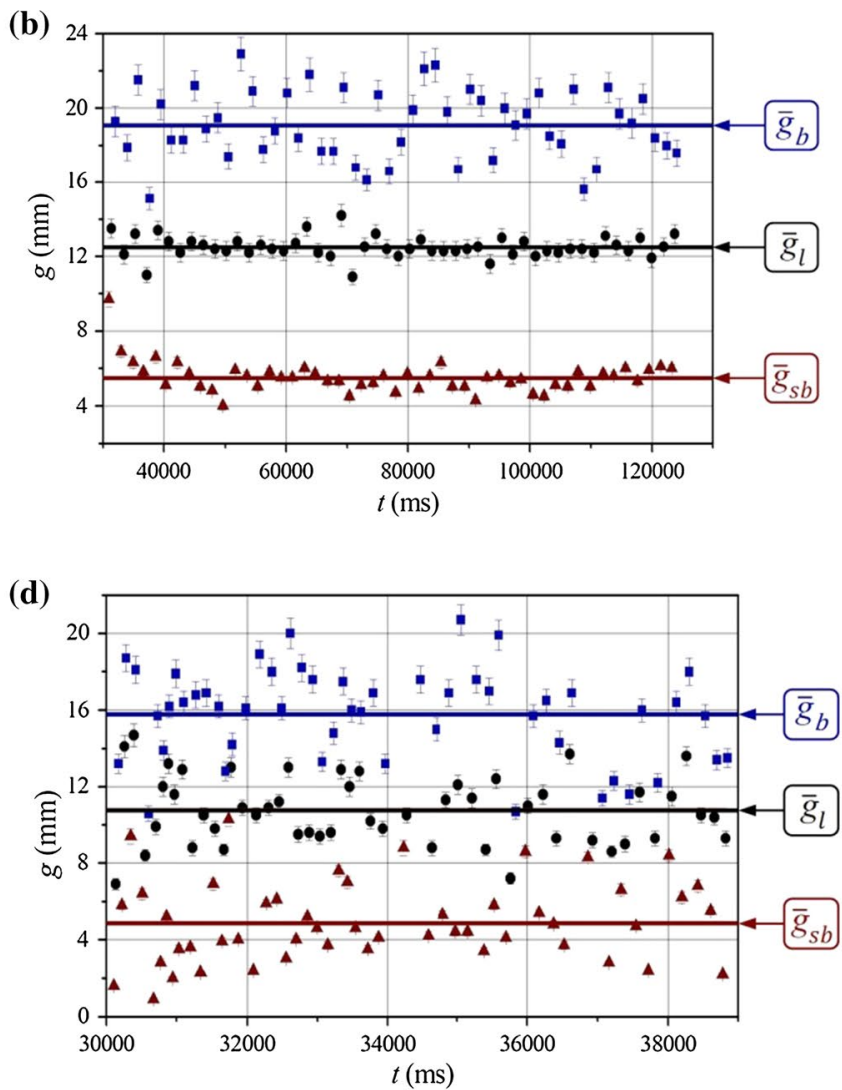

Fig. 8 Distribution of the average values of the depths of gas structures for the flows of the slug type: a LIW0005, b LIW0003 and the flows of the plug type: c LIW0004, d LIW0002 
diversity of the average depths of gas structures (Fig. 8a, b) than the flows of the plug type (Fig. 8c, b).

In order to present a supplementary description of the gas structures which arise in the flow, one defined the following non-dimensional quantities:

(a) the ratio of average depth of the large gas structure $\bar{g}_{1}$ to the average depth of a large bubble $\bar{g}_{\mathrm{b}}$, which may be represented by the following relationship:

$\xi_{1}=\frac{\bar{g}_{1}}{\bar{g}_{\mathrm{b}}}$

(b) the ratio of the average depth of small gas structures $\bar{g}_{\mathrm{sb}}$ located between large bubbles, to the average depth of large bubbles $\bar{g}_{\mathrm{b}}$ :

$$
\xi_{\mathrm{s}}=\frac{\bar{g}_{\mathrm{sb}}}{\bar{g}_{\mathrm{b}}}
$$

It follows from the law of the propagation of uncertainty (Guide 1995), respectively:

$$
\begin{aligned}
& u_{\mathrm{c}}\left(\xi_{\mathrm{l}}\right)=\sqrt{\left(\frac{1}{\bar{g}_{\mathrm{b}}} u_{\mathrm{c}}\left(\bar{g}_{1}\right)\right)^{2}+\left(\frac{\bar{g}_{1}}{\left(\bar{g}_{\mathrm{b}}\right)^{2}} u_{\mathrm{c}}\left(\bar{g}_{\mathrm{b}}\right)\right)^{2}} \\
& u_{\mathrm{c}}\left(\xi_{\mathrm{s}}\right)=\sqrt{\left(\frac{1}{\bar{g}_{\mathrm{b}}} u_{\mathrm{c}}\left(\bar{g}_{\mathrm{sb}}\right)\right)^{2}+\left(\frac{\bar{g}_{\mathrm{sb}}}{\left(\bar{g}_{\mathrm{b}}\right)^{2}} u_{\mathrm{c}}\left(\bar{g}_{\mathrm{b}}\right)\right)^{2}}
\end{aligned}
$$

Considering the fact that the values in Table 3 are values derived from a sample and not for the whole measurement, one provided the values of uncertainty for $\xi_{1}$ and $\xi_{s}$, as extended uncertainties:

$u_{\mathrm{C}}(\xi)=\chi \cdot u_{\mathrm{c}}(\xi)$

where the extension coefficient $\chi=2$.

Table 4 presents the values $\xi_{1}$ and $\xi_{\mathrm{s}}$, along with the average value of the depth of the gas phase for the entire duration of the measurement in the particular runs. By analysing this table, one may notice that $\xi_{1}$ and $\xi_{\mathrm{s}}$ are very similar to the measurements which are described regardless of the type of the flow and the velocity of the flow of the particular phases.

\section{Determining the length of the gas structure}

The length of the structures in a two-phase liquid-gas flow may be described in two basic domains: time and frequency (Zych et al. 2014). Even though both types of flow, i.e. slug and plug, are similar to each other, one may also distinguish such features in the domain of time and in the domain of frequency that set them apart.

In order to perform a frequency analysis, one used the module of cross-spectral density function (CSDF). Zych et al. (2014) show that the CSDF function is emphasised more efficiently the characteristic frequencies, including those associated with a useful signal, than the traditional autospectral density function. On the basis of Bendat and Piersol (2010), the cross-spectral density function $\underline{G}_{x y}(f)$ is determined by the following relationship:

Table 3 Average values of the depths of gas structures, standard deviations and uncertainties for 50 fragments of the measurements which were analysed

\begin{tabular}{llllllllll}
\hline Run & $\bar{g}_{1}(\mathrm{~mm})$ & $\sigma_{1}(\mathrm{~mm})$ & $u_{\mathrm{c}}\left(\bar{g}_{1}\right)(\mathrm{mm})$ & $\bar{g}_{\mathrm{b}}(\mathrm{mm})$ & $\sigma_{\mathrm{b}}(\mathrm{mm})$ & $u_{\mathrm{c}}\left(\bar{g}_{\mathrm{b}}\right)(\mathrm{mm})$ & $\bar{g}_{\mathrm{sb}}(\mathrm{mm})$ & $\sigma_{\mathrm{sb}}(\mathrm{mm})$ & $u_{\mathrm{c}}\left(\bar{g}_{\mathrm{sb}}\right)(\mathrm{mm})$ \\
\hline LIW0005 & 16.0 & 0.4 & 0.1 & 25.4 & 0.5 & 0.1 & 5.4 & 1.0 & 0.1 \\
LIW0003 & 12.5 & 0.6 & 0.1 & 19.1 & 1.8 & 0.3 & 4.7 & 0.8 & 0.1 \\
LIW0004 & 11.7 & 2.9 & 0.4 & 17.2 & 3.2 & 0.5 & 4.4 & 2.3 & 0.3 \\
LIW0002 & 10.8 & 1.8 & 0.3 & 15.8 & 2.4 & 0.3 & 4.1 & 2.1 & 0.3 \\
\hline
\end{tabular}

Table 4 Average value of the depth $g_{\mathrm{G}}$ of the gas phase for the particular measurements which are analysed and the values $\xi_{1}$ and $\xi_{\mathrm{s}}$, calculated on the basis of the average values in along with the uncertainties of the measurement

\begin{tabular}{lllllll}
\hline Run & $g_{\mathrm{G}}(\mathrm{mm})$ & $u_{\mathrm{c}}\left(g_{\mathrm{G}}\right)(\mathrm{mm})$ & $\xi_{\mathrm{l}}(-)$ & $u_{\mathrm{C}}\left(\xi_{\mathrm{l}}\right)(-)$ & $\xi_{\mathrm{s}}(-)$ & 0.25 \\
\hline LIW0005 & 15.8 & 0.6 & 0.63 & 0.01 & 0.02 & 0.29 \\
LIW0003 & 12.3 & 0.5 & 0.65 & 0.02 & 0.02 \\
LIW0004 & 11.1 & 0.4 & 0.68 & 0.06 & 0.30 & 0.04 \\
LIW0002 & 10.4 & 0.4 & 0.68 & 0.04 & 0.31 & 0.04 \\
\hline
\end{tabular}


$\underline{G}_{x y}(f)=2 \int_{-\infty}^{\infty} R_{x y}(\tau) e^{-j 2 \pi \cdot f \cdot \tau} \mathrm{d} \tau$

and the model CSDF is determined by this relationship:

$\left|\underline{G}_{x y}(f)\right|=\left\{\operatorname{Re}\left[\underline{G}_{x y}(f)\right]^{2}+\operatorname{Im}\left[\underline{G}_{x y}(f)\right]^{2}\right\}^{0.5}$

where $f$ is the frequency.

\section{Slug flow}

Figure $9 \mathrm{a}, \mathrm{b}$ presents fragments of the original signals in the domain of time for the measurements LIW0005 and LIW0003 identified as flows of the slug type. Large red frames indicate where the flow of a large bubble of gas was registered, whereas small orange frames indicate the movement of small gas structures, which consist of small bubbles. Due to a substantial level of noise, the gas structures
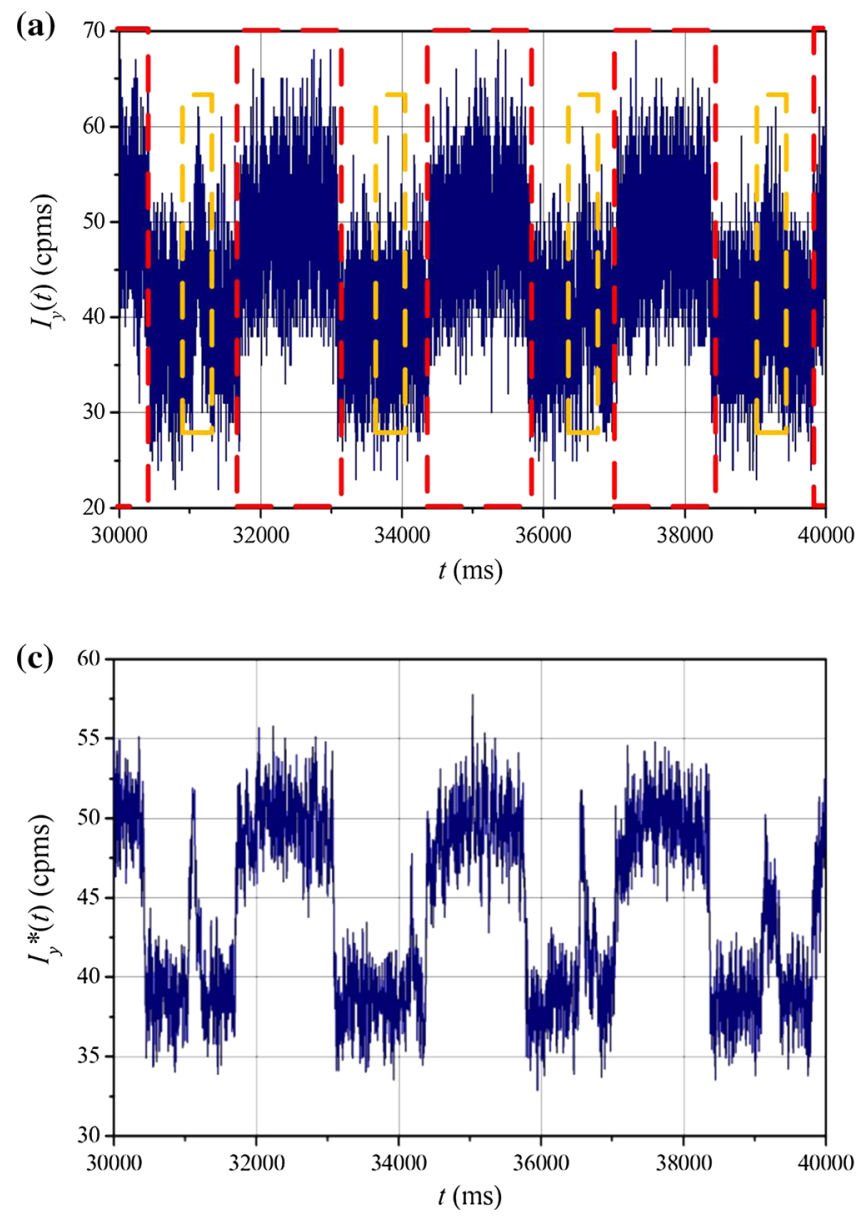

Fig. 9 Fragments of signals registered between $30 \mathrm{~s}$ and $40 \mathrm{~s}$ for the experiments: a LIW0005 - the original signal, b LIW0003-the original signal, c LIW0005-the signal after the application of smoothing between large bubbles are indicated considerably more faintly. Therefore, in order to present a clearer picture of the structure, one applied the procedure of smoothing by means of a moving average with a window whose duration is $10 \mathrm{~ms}$. The signals produced after the operation of averaging are presented in Fig. 9c, d, respectively.

Even though the noise, which originates, i.e. in a stochastic process associated with the emission of gamma quanta by a radioactive source, distorts the signal, one may provide an approximate image of it by means of a rectangular run. Thus, the signal which is registered should constitute superposition of numerous signals of this kind which are generated as a result of the flow of large bubbles with a free surface and the much smaller bubbles which are located between them. For such signals in the ICSDFl spectrum, in the range of a useful signal, indicated in Fig. 10a, b with a single-point framed line, there occur dominant frequencies. It follows from the theory of signals that a rectangular signal should generate, apart from the dominant frequency $f_{0}$, also harmonic frequencies of values which are odd multiples of
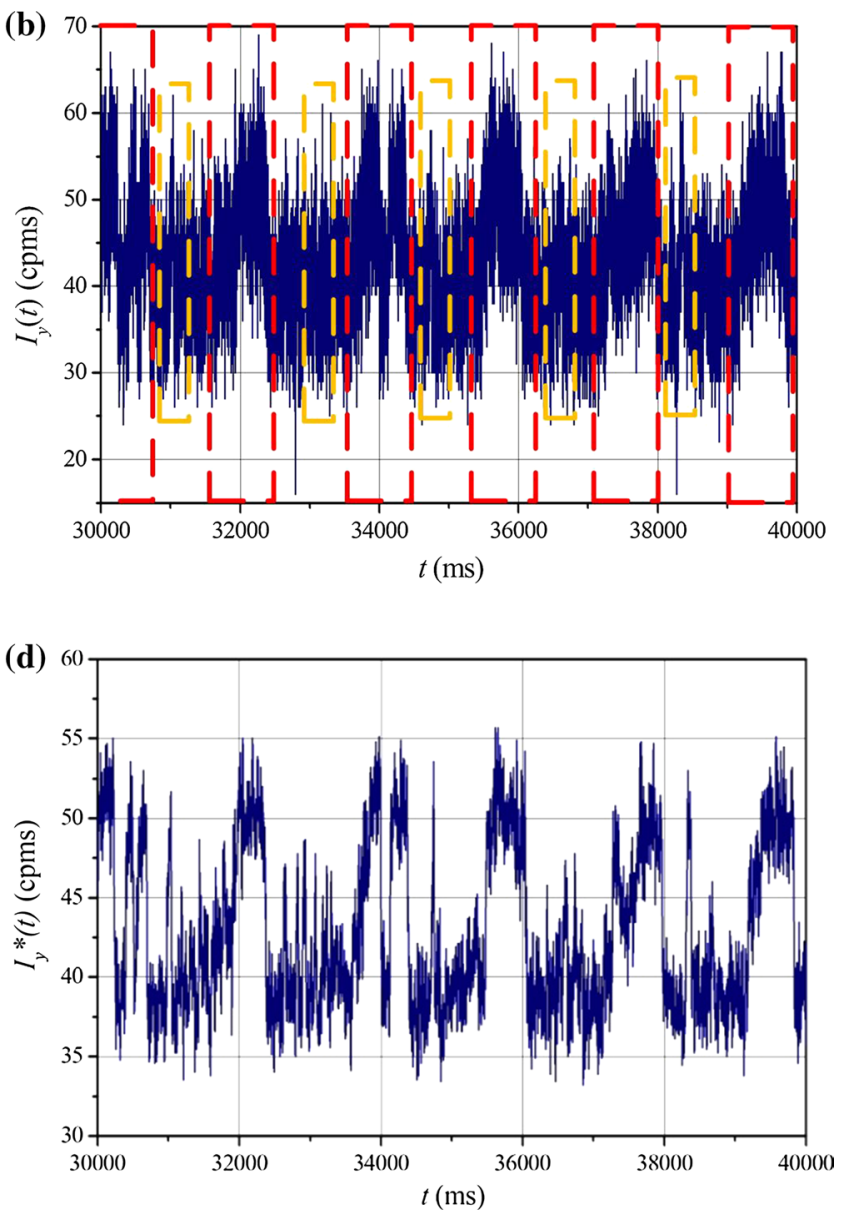

with a moving average, $\mathbf{d}$ LIW0003 - the signal after the application of smoothing with a moving average 

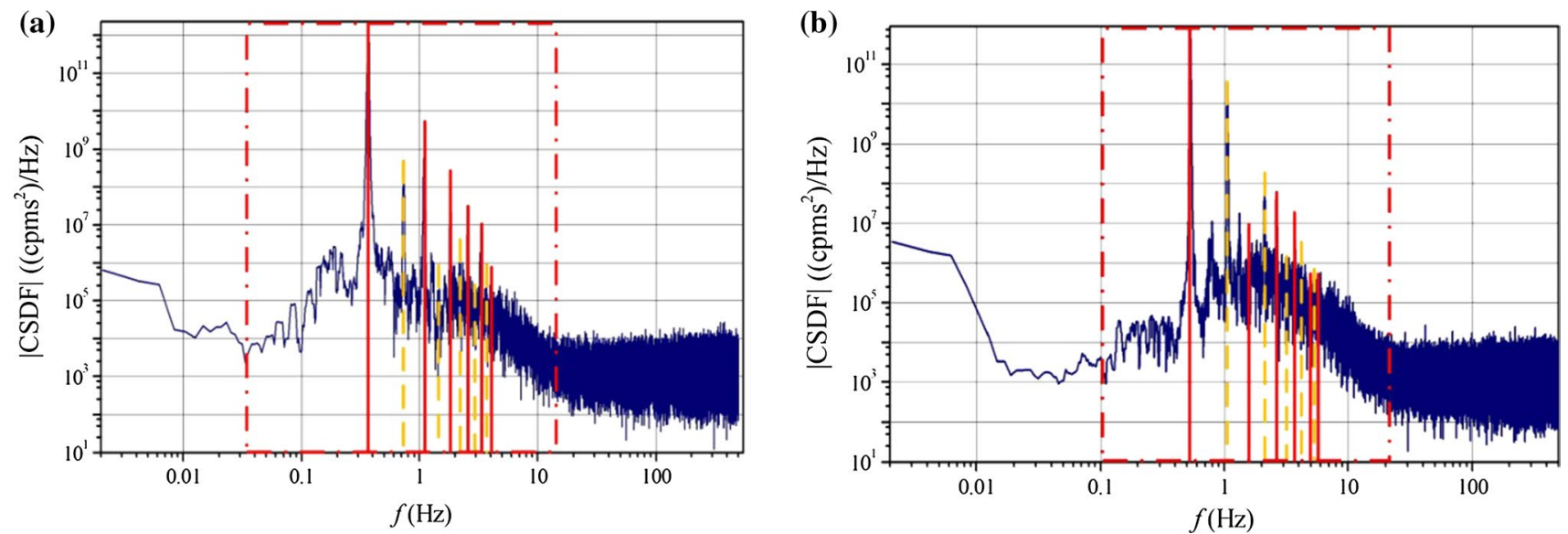

Fig. 10 ICSDFl spectra of the signals from radiometric probes in a flow of the slug type for the measurements: a LIW0005 (Zych et al. 2018 ), b LIW0003

Table 5 Values of the frequencies which dominate in a ICSDFI spectrum for the slugtype flow and the successive numbers of the harmonic $r$ of the basic frequency $f_{0}$

\begin{tabular}{lrrrr}
\hline \multicolumn{2}{l}{ LIW0005 } & & \multicolumn{2}{l}{ LIW0003 } \\
\cline { 1 - 1 } \cline { 5 - 5 }$f_{\mathrm{r}}(\mathrm{Hz})$ & $r(-)$ & & $f_{\mathrm{r}}(\mathrm{Hz})$ & $r(-)$ \\
\hline$f_{0}=0.36$ & 1 & & $f_{0}=0.53$ & 1 \\
0.73 & 2 & & 1.06 & 2 \\
1.09 & 3 & & 1.57 & 3 \\
1.47 & 4 & & 2.12 & 4 \\
1.83 & 5 & & 2.65 & 5 \\
2.20 & 6 & & 3.16 & 6 \\
2.57 & 7 & & 3.71 & 7 \\
2.91 & 8 & & 4.20 & 8 \\
3.27 & 9 & & 4.75 & 9 \\
3.65 & 10 & & 5.29 & 10 \\
4.01 & 11 & & 5.79 & 11 \\
\hline
\end{tabular}

$f_{0}$. The graphs in Fig. 10a, $\mathrm{b}$ and Table 5 indicate that such harmonic frequencies (indicated by a solid red line in the graphs) are a part of the ICSDFI spectrum. However, apart from these frequencies there are also harmonic frequencies which are even multiples of $f_{0}$ (indicated by a dashed orange line in Fig. 10a, b). Eventually, the dominant frequencies in the range of the useful signal may be described by the following formula:

$f_{r}=r \cdot f_{0}$

where $r \in\{1,2, \ldots\}$ is the number of subsequent harmonic frequency.

The linking of dominant frequencies with a flow is possible only by performing a supplementary analysis of the signal in the domain of time, i.e. by establishing the duration of a large gas structure $t_{1}$ (Fig. 7). It is also crucial to determine the duration of a large bubble $t_{\mathrm{b}}$. By taking into consideration the average velocity of the movement of the gas phase, one may calculate their lengths.

The instantaneous lengths of large structures are defined by the following relationship (Zych et al. 2018):

$l_{1}=t_{1} \cdot v_{\mathrm{G}}$

similarly in the case of a large bubble:

$l_{\mathrm{b}}=t_{\mathrm{b}} \cdot v_{\mathrm{G}}$

On the basis of the law of the propagation of uncertainty, one may establish the complex uncertainty of a measurement of the length of a structure:

$u_{\mathrm{c}}\left(l_{1}\right)=\sqrt{\left(v_{\mathrm{G}} \cdot u_{\mathrm{B}}\left(t_{1}\right)\right)^{2}+\left(t_{1} \cdot u_{\mathrm{c}}\left(v_{\mathrm{G}}\right)\right)^{2}}$

Considering the fact that the sampling time is $\Delta t=1 \mathrm{~ms}$, one assumed the estimated uncertainty of the duration of the structure $u_{\mathrm{B}}\left(t_{1}\right)=2 \mathrm{~ms}$.

Figure $11 \mathrm{a}, \mathrm{b}$ presents the distributions of the lengths of large gas structures (indicated by black circles) and the lengths of the bubbles (small blue squares). Continuous lines indicate average values: $\bar{l}_{1}$-the lengths of large structures (black line), $\bar{l}_{\mathrm{b}}$-the lengths of large bubbles (blue line). Table 6 contains average values of the lengths of the structures along with the respective standard deviations and the uncertainties of a measurement.

The values of the lengths of the structures obtained on the basis of an analysis of the signal in the domain of time are congruous with the supplementary photographical documentation. On this basis, one estimated the length of a large structure, which was about $3.6 \mathrm{~m}$ for the LIW0005 measurement, whereas the length of the bubble was about $1.8 \mathrm{~m}$. For the LIW0003 measurement, the length of a large structure was about $3.4 \mathrm{~m}$, and the length of a large bubble was about $1.7 \mathrm{~m}$. 
Identification of the salient frequencies may be conducted by taking the reverse of the duration values $t_{1}$ and $t_{\mathrm{b}}$. On this basis, one may calculate the average frequency for a large structure $\bar{f}_{1}$, from the following relationship:

$\bar{f}_{1}=\frac{1}{\bar{t}_{1}}$

and the average frequency for a large gas bubble $\bar{f}_{\mathrm{b}}$ :

$\bar{f}_{\mathrm{b}}=\frac{1}{\bar{t}_{\mathrm{b}}}$

Table 7 presents the values of the frequencies $\bar{f}_{1}$ and $\bar{f}_{\mathrm{b}}$, calculated on the basis of formulae (Eq. 23) and (Eq. 24).

When one analyses Tables 5 and 7, one may notice considerable congruity of the frequencies $\bar{f}_{1}=f_{0}$ and $\bar{f}_{\mathrm{b}}=f_{2}$ in both of the measurements which were analysed. One may draw a conclusion that one should interpret these frequencies to be directly associated with an average size and with the movement of large gas structures and large bubbles. One this basis, one may provide a relationship which describes

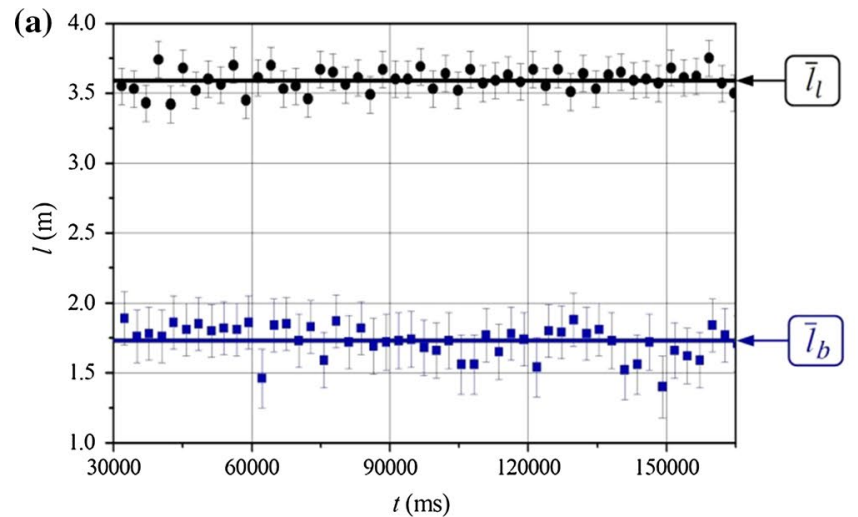

the average duration of gas structures for a flow of the slug type (Zych et al. 2018):

$\bar{l}_{1}=\frac{v_{\mathrm{G}}}{f_{0}}$

and for large gas bubbles:

$\bar{l}_{\mathrm{b}}=\frac{v_{\mathrm{G}}}{f_{2}}=\frac{v_{\mathrm{G}}}{2 \cdot f_{0}}$

A physical analysis of the successive frequencies which are multiples of $f_{0}$ is more difficult due to the fact that their footprint in the radioisotope signal is weaker. By analysing the photographical documentation and by comparing it with the signals which were analysed, one may state that it is necessary to associate even frequencies of higher orders with the movement of smaller gas structures, located in the space between large bubbles.

Eventually, it followed from the ICSDFI analysis that the average length of gas structures for the LIW0005 measurement is $\bar{l}_{1}=(3.64 \pm 0.15) \mathrm{m}$, whereas for the LIW0003 it is $\bar{l}_{1}=(3.37 \pm 0.11) \mathrm{m}$. The average length of large bubbles for

Fig. 11 Distributions of the values of the lengths of gas structures for flows of the slug type: a LIW0005, b LIW0003

Table 6 Average values of the lengths of the structures $\bar{l}_{1}$ and $\bar{l}_{\mathrm{b}}$ along with the standard deviations $\sigma_{\mathrm{l}}, \sigma_{\mathrm{b}}$ and the uncertainties $u_{\mathrm{c}}\left(\bar{l}_{1}\right), u_{\mathrm{c}}\left(\bar{l}_{\mathrm{b}}\right)$ for flows of the slug type

\begin{tabular}{lcccccc}
\hline Run & $\bar{l}_{1}(\mathrm{~m})$ & $\sigma_{\mathrm{l}}(\mathrm{m})$ & $u_{\mathrm{c}}\left(\bar{l}_{1}\right)(\mathrm{m})$ & $\bar{l}_{\mathrm{b}}(\mathrm{m})$ & $\sigma_{\mathrm{b}}(\mathrm{m})$ & $u_{\mathrm{c}}\left(\bar{l}_{\mathrm{b}}\right)(\mathrm{m})$ \\
\hline LIW0005 & 3.59 & 0.08 & 0.14 & 1.73 & 0.11 & 0.07 \\
LIW0003 & 3.38 & 0.24 & 0.11 & 1.68 & 0.26 & 0.06 \\
\hline
\end{tabular}

Table 7 Values of the average durations of gas structures $\bar{t}_{1}, \bar{t}_{\mathrm{b}}$ and the corresponding frequencies $\bar{f}_{\mathrm{l}}$ and $\bar{f}_{\mathrm{b}}$

$$
\text { frequencies } f_{1} \text { and } f_{\mathrm{b}}
$$

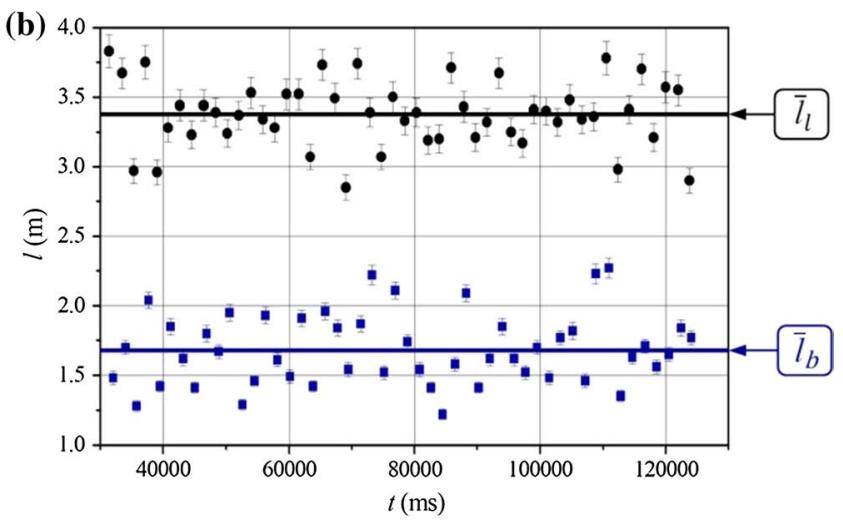

\begin{tabular}{|c|c|c|c|c|c|c|c|}
\hline \multicolumn{4}{|c|}{ LIW0005 } & \multicolumn{4}{|c|}{ LIW0003 } \\
\hline $\bar{t}_{1}(\mathrm{~ms})$ & $\bar{f}_{1}(\mathrm{~Hz})$ & $\bar{t}_{\mathrm{b}}(\mathrm{ms})$ & $\bar{f}_{\mathrm{b}}(\mathrm{Hz})$ & $\bar{t}_{1}(\mathrm{~ms})$ & $\bar{f}_{1}(\mathrm{~Hz})$ & $\bar{t}_{\mathrm{b}}(\mathrm{ms})$ & $\bar{f}_{\mathrm{b}}(\mathrm{Hz})$ \\
\hline 2712 & 0.37 & 1305 & 0.77 & 1885 & 0.53 & 940 & 1.06 \\
\hline
\end{tabular}


the LIW0005 measurement is $\bar{l}_{\mathrm{b}}=(1.81 \pm 0.07) \mathrm{m}$, and for the LIW0003 measurement, it is $\bar{l}_{\mathrm{b}}=(1.69 \pm 0.05) \mathrm{m}$. By comparing these results with the values indicated in Table 6 , one may observe that there is a considerable congruity of the values obtained due to an analysis of the signal in the domain of time and frequency.

As far as the modelling of signals is concerned, the average duty cycle, which may be defined in the following way for the measurements which were performed, is also important:

$\zeta_{\mathrm{t}}=\frac{\bar{t}_{\mathrm{b}}}{\bar{t}_{1}}$

$\zeta_{\mathrm{f}}=\frac{f_{0}}{f_{2}}$

After an analysis of a sample of 50 fragments of the signal for the LIW0005 measurement, one established $\zeta_{\mathrm{t}}=0.48$ and $\zeta_{\mathrm{f}}=0.50$. As far as the LIW0003 measurement is concerned, the average duty cycle is $\zeta_{\mathrm{t}}=\zeta_{\mathrm{f}}=0.50$, respectively.

\section{Plug flow}

The flow of the plug type, despite many similarities to the flow of the slug type, also manifests features which are peculiar only to itself in reference to the signal which was registered, both in the domain of time and in the domain of frequency.

Figure $12 \mathrm{a}, \mathrm{b}$ presents signals from radioisotope probes registered in the LIW0004 and LIW0002 measurements.

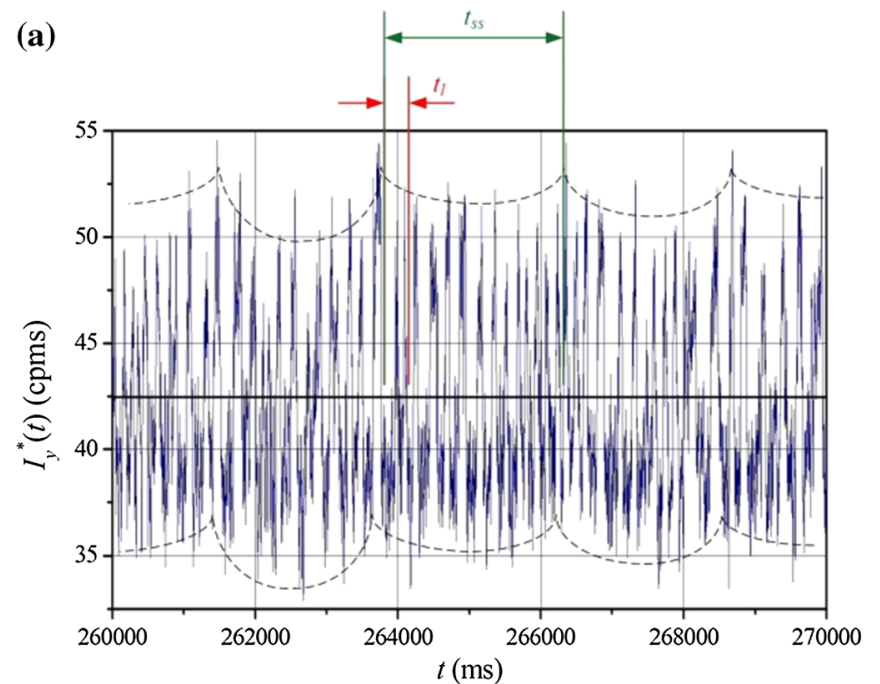

The flow of this type features a basic (large) structure which consists of a large gas bubble (whose duration is $t_{1}$ ), and whose length is considerably smaller than in the case of the slug flows (images in Fig. 3c, d), as well as the area in which smaller bubbles are located. Moreover, on the basis of an analysis of the signal, one may distinguish one more greater structure-the so-called superstructure (duration $t_{\mathrm{ss}}$, which consists of a few or of up to a dozen or so basic structures.

The graphs in Fig. 13a, b present the distributions of the lengths of large structures and bubbles calculated according to the relationships (Eqs. 20, 21) for selected subsequent 50 fragments of signals in the LIW0004 and LIW0002 measurements.

A comparison of the graphs in Fig. 11a, b with the graphs in Fig. 13a, b, as well as Tables 6 and 8, demonstrates that not only gas structures in the flow of the plug type are shorter but also the relative variation of their length is greater than in the case of the flows of the slug type.

Considerable variation of the depths of gas structures (Fig. 7c, d) and their lengths may be caused by the existence of superstructures of a gas phase. The distribution of the lengths of these superstructures for the 50 fragments of the signals is indicated by the graphs in Fig. 14a, b. The lengths of the superstructures of gas were calculated analogously as in the case of gas structures (Eq. 20). In both graphs, the average value of their lengths $\bar{l}_{\mathrm{ss}}$ was indicated by means of a continuous line, whereas Table 9 presents the average values of the lengths of the superstructures, their uncertainties $u_{c}\left(\bar{l}_{\mathrm{ss}}\right)$ and standard deviations $\sigma_{\mathrm{ss}}$. On the basis of an analysis which was performed, one stated that the superstructures consist of two to 21 large gas structures.

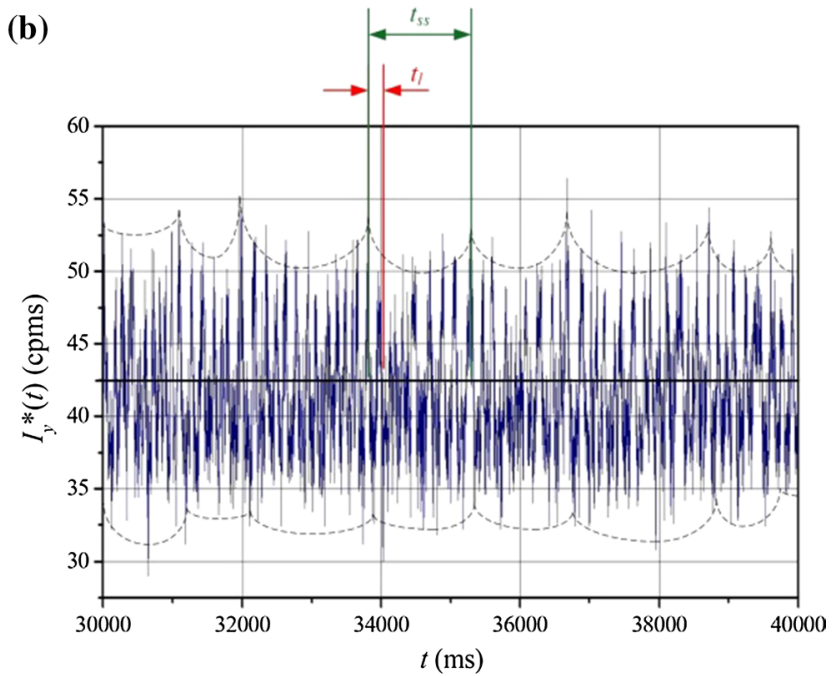

Fig. 12 Fragments of signals from radiometric probes for the flows of the plug type, obtained in the measurements: a LIW0004, b LIW0002 

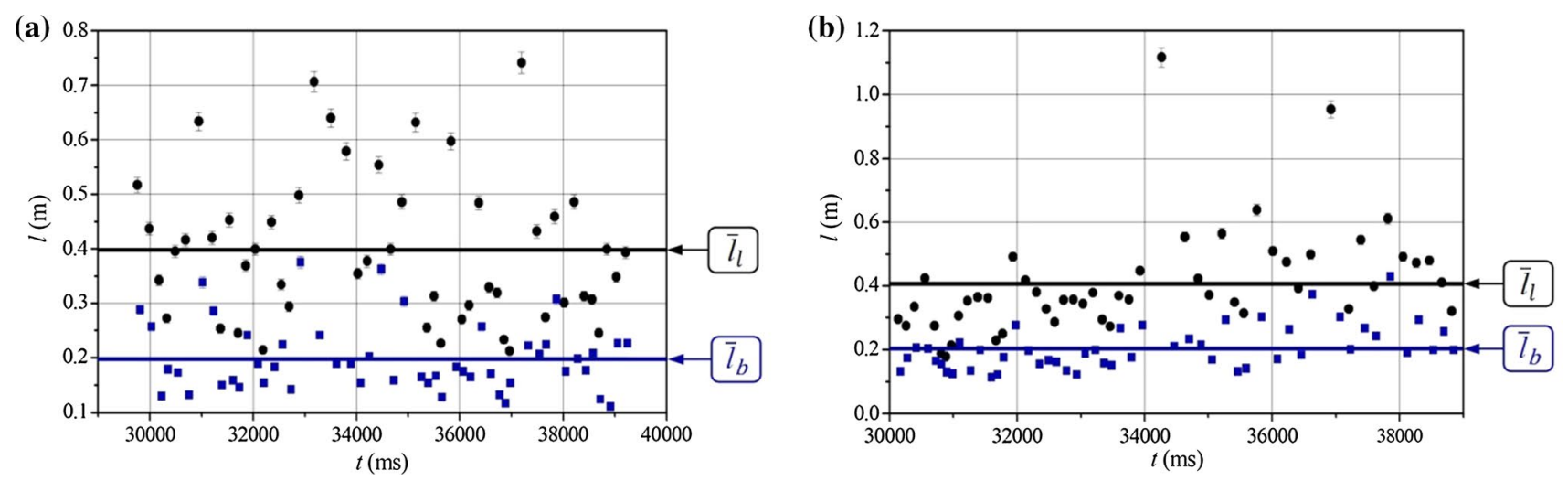

Fig. 13 Distribution of the values of the lengths of gas structures for the flows of the plug type: a LIW0004, b LIW0002

Table 8 Average values of the lengths of structures $\bar{l}_{1}$ and $\bar{l}_{\mathrm{b}}$ along with the standard deviations $\sigma_{\mathrm{l}}, \sigma_{\mathrm{b}}$ and the uncertainties $u_{\mathrm{c}}\left(\bar{l}_{1}\right), u_{\mathrm{c}}\left(\bar{l}_{\mathrm{b}}\right)$ for the flows of the plug type

\begin{tabular}{lllllll}
\hline Run & $\bar{l}_{1}(\mathrm{~m})$ & $\sigma_{1}(\mathrm{~m})$ & $u_{\mathrm{c}}\left(\bar{l}_{1}\right)(\mathrm{m})$ & $\bar{l}_{\mathrm{b}}(\mathrm{m})$ & $\sigma_{\mathrm{b}}(\mathrm{m})$ & $u_{\mathrm{c}}\left(\bar{l}_{\mathrm{b}}\right)(\mathrm{m})$ \\
\hline LIW0004 & 0.398 & 0.134 & 0.021 & 0.198 & 0.063 & 0.010 \\
LIW0002 & 0.406 & 0.167 & 0.026 & 0.202 & 0.067 & 0.011 \\
\hline
\end{tabular}

(a)

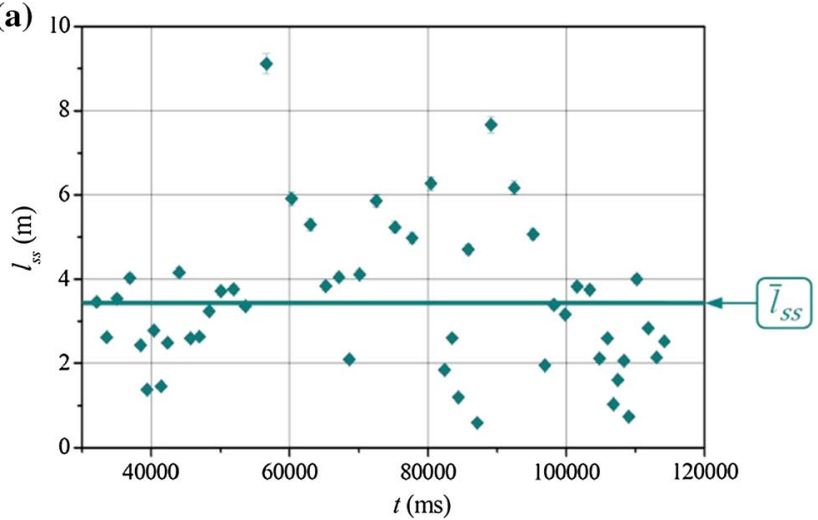

(b)

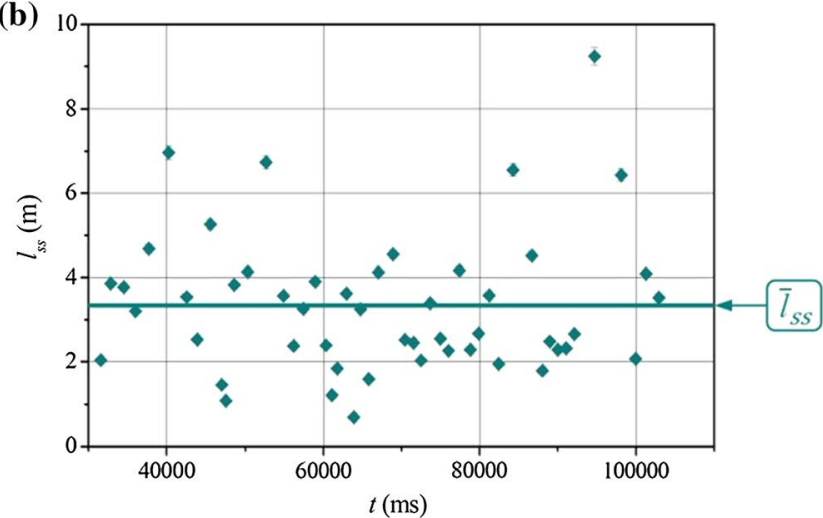

Fig. 14 Distribution of the values of the gas superstructures for the flows of the plug type: a LIW0004, b LIW0002

Such a form of durations (Fig. 12a, b) manifests itself in a peculiar way in the domain of frequency. ICSDFI spectra for the measurements which were analysed are illustrated by the graphs in Fig. 15a, b. In these graphs, the frame (1) indicates the range in which the dominant frequency $f_{0}$ is located, whereas the frame (2) indicates the range of the useful signal, for which the maximum is indicated by a purple dashed line-the frequency $f_{\mathrm{u}}$. Table 10 presents the values $f_{0}$ and $f_{\mathrm{u}}$ for both measurements which were analysed.

Similarly as in the case of the flow of the slug type (Chapter 4.3.1), also in this case the association of the frequency (frequencies) with physical phenomena which occur in a flow
Table 9 Average lengths of the superstructures $\bar{l}_{\mathrm{ss}}$ with the standard deviation $\sigma_{\mathrm{ss}}$ and the uncertainty of the measurement $u_{\mathrm{c}}\left(\bar{l}_{\mathrm{ss}}\right)$, for the measurement of the plug type

\begin{tabular}{llll}
\hline Run & $\bar{l}_{\mathrm{ss}}(\mathrm{m})$ & $\sigma_{\mathrm{ss}}(\mathrm{m})$ & $u_{\mathrm{c}}\left(\bar{l}_{\mathrm{ss}}\right)(\mathrm{m})$ \\
\hline LIW0004 & 3.44 & 1.75 & 0.09 \\
LIW0002 & 3.34 & 1.67 & 0.09 \\
\hline
\end{tabular}




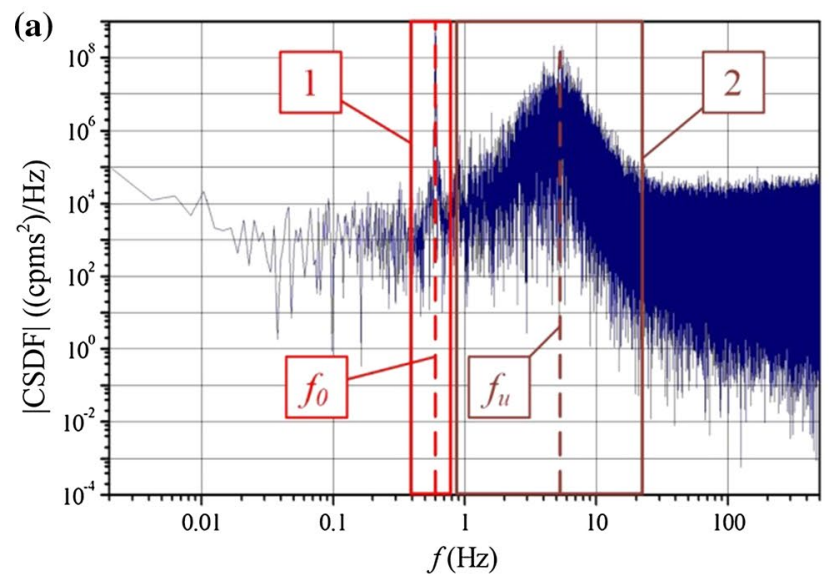

Fig. 15 ICSDF| spectra for the measurements: a LIW0004, b LIW0002

Table 10 Values of the dominant frequencies $f_{0}$ and $f_{\mathrm{u}}$ in the ICSDFI spectrum for the flow of the plug type

\begin{tabular}{lll}
\hline Run & $f_{0}(\mathrm{~Hz})$ & $f_{\mathrm{u}}(\mathrm{Hz})$ \\
\hline LIW0004 & 0.60 & 5.18 \\
LIW0002 & 0.67 & 5.70 \\
\hline
\end{tabular}

may be conducted by calculating the frequencies for the average durations of the flow of gas structures. Hence, one may calculate the frequency for the average duration of a superstructure $\bar{t}_{\mathrm{ss}}$ :

$\bar{f}_{\mathrm{ss}}=\frac{1}{\bar{t}_{\mathrm{ss}}}$

whereas for the average duration of a large gas structure $\bar{t}_{1}$ and the average duration of a large bubble $\bar{t}_{\mathrm{b}}$, the respective frequencies are calculated according to the formulae (Eqs. 23, 24). Table 11 presents a average durations $\bar{t}_{\mathrm{ss}}, \bar{t}_{1}, \bar{t}_{\mathrm{b}}$ and the corresponding frequencies $\bar{f}_{\mathrm{ss}}, \bar{f}_{1}$ and $\bar{f}_{\mathrm{b}}$.

It follows from a comparison of Tables 10 and 11 that there is a considerable congruity of the values of the frequencies $\bar{f}_{\text {ss }}$ and $f_{0}$ as well as $\bar{f}_{1}$ and $f_{\mathrm{u}}$. Hence, it follows that the dominant frequency $f_{0}$ should be associated with the flow of superstructures. Therefore, the average length of a superstructure may be calculated on the basis of the following formula:

$\bar{l}_{\mathrm{ss}}=\frac{v_{\mathrm{G}}}{f_{0}}$

This implies the establishment of a dependency on the complex uncertainty of $\bar{l}_{\mathrm{ss}}$ :

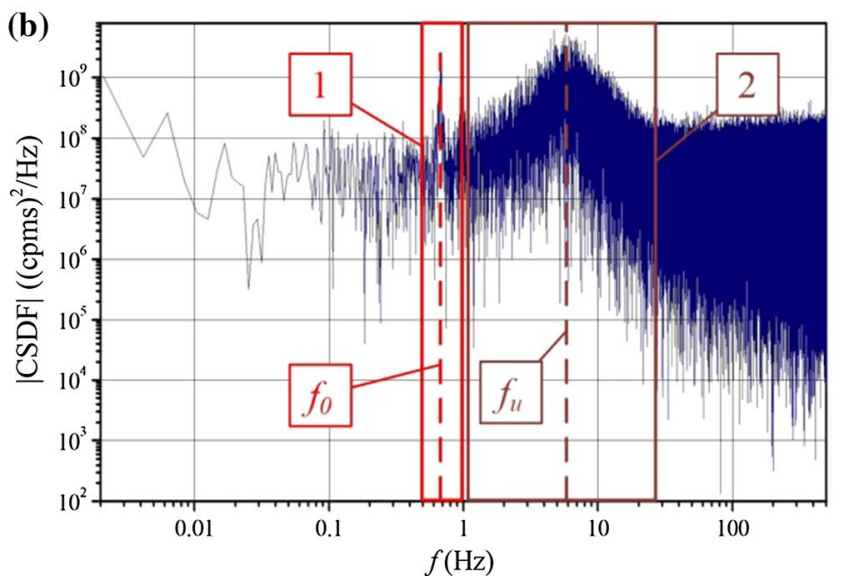

$u_{\mathrm{c}}\left(\bar{l}_{\mathrm{ss}}\right)=\sqrt{\left(\frac{1}{f_{0}} u_{\mathrm{c}}\left(v_{\mathrm{G}}\right)\right)^{2}+\left(\frac{v_{\mathrm{G}}}{\left(f_{0}\right)^{2}} u_{\mathrm{B}}\left(f_{0}\right)\right)^{2}}$

The uncertainty $u_{\mathrm{B}}\left(f_{0}\right)$ was assumed to be equal to $0.0042 \mathrm{~Hz}$, which results from the precision of the interpretation of the value of the frequency $f_{0}$ from the ICSDF| spectrum.

On the basis of the analyses which were performed, one may claim that the length of a superstructure calculated on the basis of the formula (Eq. 28) for the measurement LIW0004 is: $\bar{l}_{\mathrm{ss}}=(3.43 \pm 0.09) \mathrm{m}$, whereas for the measurement LIW0002: $\bar{l}_{\mathrm{ss}}=(3.41 \pm 0.09) \mathrm{m}$. The considerations which were conducted also indicate that the frequency $f_{0}$ is responsible for the modulations of the amplitude of the signal in the domain of time.

The equality of frequencies $f_{1}$ and $f_{\mathrm{u}}$ allows to write an alternative dependence on the length $l_{1}$ in relation to the formula (Eq. 20):

$\bar{l}_{1}=\frac{v_{\mathrm{G}}}{f_{\mathrm{u}}}$

while the complex uncertainty $u_{c}\left(\bar{l}_{l}\right)$ may be described by a dependency similar to (Eq. 29).

By analysing the average duty cycle $\zeta_{t}$, calculated on the basis of data presented in Table 8 , one may claim that for both measurements-LIW0004 and LIW0002- $\zeta_{t} \approx 0.50$. Therefore, one may present the expression which refers to the average length of a large bubble as:

Table 11 Average values of the durations of superstructures $\bar{t}_{\mathrm{ss}}$ and gas structures $\bar{t}_{\mathrm{l}}, \bar{t}_{\mathrm{b}}$ and the corresponding frequencies $\bar{f}_{\mathrm{ss}}, \bar{f}_{1}$ and $\bar{f}_{\mathrm{b}}$

\begin{tabular}{|c|c|c|c|c|c|c|c|c|c|c|c|}
\hline \multicolumn{6}{|c|}{ LIW0004 } & \multicolumn{6}{|c|}{ LIW0002 } \\
\hline $\bar{t}_{\mathrm{ss}}(\mathrm{ms})$ & $\bar{f}_{\mathrm{ss}}(\mathrm{Hz})$ & $\bar{t}_{1}(\mathrm{~ms})$ & $\bar{f}_{1}(\mathrm{~Hz})$ & $\bar{t}_{\mathrm{b}}(\mathrm{ms})$ & $\bar{f}_{\mathrm{b}}(\mathrm{Hz})$ & $\bar{t}_{\mathrm{ss}}(\mathrm{ms})$ & $\bar{f}_{\mathrm{ss}}(\mathrm{Hz})$ & $\bar{t}_{1}(\mathrm{~ms})$ & $\bar{f}_{1}(\mathrm{~Hz})$ & $\bar{t}_{\mathrm{b}}(\mathrm{ms})$ & $\bar{f}_{\mathrm{b}}(\mathrm{Hz})$ \\
\hline 1670 & 0.60 & 193 & 5.17 & 96 & 10.38 & 1452 & 0.69 & 176 & 5.67 & 88 & 11.38 \\
\hline
\end{tabular}


$\bar{l}_{\mathrm{b}}=\frac{v_{\mathrm{G}}}{2 \cdot f_{\mathrm{u}}}$

The calculations which were made on the basis of the equations (Eqs. 32, 33) enable us to estimate the average length of gas structures for the LIW0004 measurement $\bar{l}_{1}=(0.398 \pm 0.010) \mathrm{m}$ and for LIW0002 $\bar{l}_{1}=(0.404 \pm 0.011)$ $\mathrm{m}$, whereas the lengths of large bubbles for the LIW0004 measurement are $\bar{l}_{\mathrm{b}}=(0.199 \pm 0.005) \mathrm{m}$, and for LIW0002 measurement $\bar{l}_{\mathrm{b}}=(0.202 \pm 0.05) \mathrm{m}$.

\section{Conclusion}

The article presents an analysis of the signals from the radiometric measurement system for the absorption of gamma rays which consists of a set of two scintillation probes and from two sealed sources of Am-241. The analyses were performed in the time and frequency domain for intermittent flows of the slug and plug types. One distinguished the parameters of signals which were associated with physical quantities of the mixture which flowed. The amplitudes of the signals were associated with the depth of gas structures, whereas the dominant frequencies were associated with the lengths of these structures. One additionally introduced nondimensional quantities for the description of the liquid-gas flow such as the average coefficient of the duty cycle $\zeta_{t}$, the relationship of the average depth of the large gas structure to the average depth of a large bubble $\xi_{1}$, and the relationship of the average depth of small gas structures located between large bubbles to the average depth of large bubbles $\xi_{\mathrm{s}}$. The obtained values of these parameters are similar for the analysed measurements.

Apart from the similarities, one also established the existence of differences of parameters of signals which occur in the time and frequency domain for the types of flows which were described.

In a flow of the slug type, there occur basic structures which consist of a large bubble and of a number of smaller structures which are situated in the space between large bubbles. The values of the amplitudes of signals from probes are at a constant level, which results in a decreased standard deviation of the estimated average depths of gas in the fragments of the gas which were analysed. In a frequency spectrum $|C S D F|$, there occur harmonic dominants which are even and odd multiples of the frequency $f_{0}$. After the results of the analysis were compared, one stated that the frequency $f_{0}$ is associated with the movement of a large gas structure. The knowledge of the average speed of the movement of gas enables the estimation of the average length of such structures. The frequency which is the double multiple of $f_{0}$ is associated with the average length of large bubbles in a large gas structure.
However, in the flow of the plug type, one may distinguish in the duration considerably greater superstructures, apart from large gas structures, which are similar to the ones in the flow of the slug type. In a frequency spectrum $|C S D F|$, this manifests itself by two salient ranges: the range of the dominant frequency $f_{0}$, associated with the flow and the average size of superstructures, and the range of the frequency of the useful signal. The harmonic dominant for this range $f_{\mathrm{u}}$ is associated with the flow and the average size of large gas structures. Hence, one may draw a conclusion that the frequency $f_{0}$ is directly associated with the modulation of the signal, i.e. periodical change of an amplitude. As a result, the standard deviation of the changes of the depths of gas structures is greater for flows of the plug type than in the case of the flows of the slug type.

On the basis of the measurements and analyses which were performed, one may develop models of signals for the liquid-gas flows in question, studied by means of the method of the absorption of gamma rays. The results which are obtained may be used in the more efficient identification of two-phase liquid-gas flows in the installations intended for hydrotransport of gas, in which there is no optical access to the mixture which flows through.

Acknowledgements The author would like to specially thank Prof. Robert Hanus, Prof. Marek Jaszczur, Dr Paweł Jodłowski, Prof. Volodymyr Mosorov, Dr Leszek Petryka, Prof. Dariusz Świsulski for their cooperation during the measurements and support in the writing of the manuscript.

Funding This publication was financed by the AGH University of Science and Technology, Faculty of Geology Geophysics and Environmental Protection (Grant No 11.11.140.645).

\section{Compliance with ethical standards}

Conflict of interest The author declares that there is no conflict of interest regarding the publication of this paper.

Open Access This article is distributed under the terms of the Creative Commons Attribution 4.0 International License (http://creativeco mmons.org/licenses/by/4.0/), which permits unrestricted use, distribution, and reproduction in any medium, provided you give appropriate credit to the original author(s) and the source, provide a link to the Creative Commons license, and indicate if changes were made.

\section{References}

Ameran HLM, Mohamad EJ, Muji SZM et al (2017) Multiphase flow velocity measurement of chemical processes using electrical tomography: a review. In: Proceedings-2016 IEEE international conference on automatic control and intelligent systems, I2CACIS 2016

Arkani M, Khalafi H, Vosoughi N, Khakshournia S (2017) Development and experimental validation of a correlation monitor tool 
based on the endogenous pulsed neutron source technique. Metrol Meas Syst 24:441-461. https://doi.org/10.1515/mms-2017-0043

Arvoh BK, Hoffmann R, Halstensen M (2012) Estimation of volume fractions and flow regime identification in multiphase flow based on gamma measurements and multivariate calibration. Flow Meas Instrum 23:56-65. https://doi.org/10.1016/j.flowmeasin st.2011.11.002

Banasiak R, Wajman R, Jaworski T, Fiderek P, Fidos H, Nowakowski J, Sankowski D (2014) Study on two-phase flow regime visualization and identification using 3D electrical capacitance tomography and fuzzy-logic classification. Int J Multiphas Flow 58:1-14. https ://doi.org/10.1016/j.ijmultiphaseflow.2013.07.003

Beck MS, Pląskowski A (1987) Cross-correlation flowmeters. Their design and application. Adam Hilger, Bristol

Bendat JS, Piersol AG (2010) Random data. Analysis and measurement procedures, 4th edn. Wiley, New York

Biswal J, Pant HJ, Goswami S et al (2018) Measurement of flow rates of water in large diameter pipelines using radiotracer dilution method. Flow Meas Instrum 59:194-200. https://doi. org/10.1016/j.flowmeasinst.2017.12.014

Buttkus B (2000) Spectral analysis and filter theory in applied geophysics. Springer, Berlin

Chaouki J, Larachi F, Dudukovic M (1997) Non-invasive monitoring of multiphase flows. Elsevier, Amsterdam

de Oliveira WR, de Paula IB, Martins FJWA, Farias PSC, Azevedo LFA (2015) Bubble characterization in horizontal air-water intermittent flow. Int J Multiph Flow 69:18-30. https://doi. org/10.1016/j.ijmultiphaseflow.2014.10.014

Falcone G, Hewitt GF, Alimonti C (2009) Multiphase flow metering: principles and applications. Elsevier, Amsterdam

García JT, Vigueras-Rodriguez A, Castillo LG, Carrillo JM (2017) Evaluation of sulfide control by air-injection in sewer force mains: field and laboratory study. Sustainability 9(3):402. https://doi. org/10.3390/su9030402

Gołębiowski T, Porzucek S, Pasierb B (2016) Ambiguities in geophysical interpretation during fracture detection-case study from a limestone quarry (Lower Silesia Region, Poland). Near Surf Geophys 14:371-384. https://doi.org/10.3997/1873-0604.2016017

Guide (1995) Guide to the expression of uncertainly in measurement. International Organization for Standardization, Geneva

Gulhane NP, Mahulikar SP (2009) Variations in gas properties in laminar micro-convection with entrance effect. Int J Heat Mass Transf 52:1980-1990. https://doi.org/10.1016/j.ijheatmasstrans fer.2008.08.037

Hanus R (2003) Statistical error analysis of time delay measurement by using phase of cross-spectral density function. Syst Anal Model Simul 43(8):993-998. https://doi.org/10.1080/023292903100008 0632

Hanus R (2009) The application of the Hilbert transform to correlation measurements of time delay. Prz Elektrotech 85(7):45-48

Hanus R (2015) Application of the Hilbert transform to measurements of liquid-gas flow using gamma ray densitometry. Int $\mathrm{J}$ Multiph Flow 72:210-217. https://doi.org/10.1016/j.ijmultipha seflow.2015.02.002

Hanus R, Petryka L, Zych M (2014) Velocity measurement of the liquid-solid flow in a vertical pipeline using gamma-ray absorption and weighted cross-correlation. Flow Meas Instrum 40:58-63. https://doi.org/10.1016/j.flowmeasinst.2014.08.007

Hanus R, Zych M, Kusy M, Jaszczur M, Petryka L (2018) Identification of liquid-gas flow regime in a pipeline using gamma-ray absorption technique and computational intelligence methods. Flow Meas Instrum 60:17-23. https://doi.org/10.1016/j.flowm easinst.2018.02.008

Heindela TH, Grayb JN, Jensenb TC (2008) An X-ray system for visualizing fluid flows. Flow Meas Instrum 19:67-78. https://doi. org/10.1016/j.flowmeasinst.2007.09.003
Jarzyna JA, Krakowska PI, Puskarczyk E, Wawrzyniak-Guz K, Bielecki J, Tkocz K, Tarasiuk J, Wroński S, Dohnalik M (2016) X-ray computed microtomography-a useful tool for petrophysical properties determination. Comput Geosci 20(5):1155-1167. https://doi. org/10.1007/s10596-016-9582-3

Jaszczur M, Portela LM (2008) Numerical data for reliability of LES for non-isothermal multiphase turbulent channel flow. In: Meyers J, Geurts B, Sagaut P (eds) Quality and reliability of largeeddy simulations. Springer, New York, pp 343-354. https://doi. org/10.1007/978-1-4020-8578-9_28

Johansen G, Jackson P (2004) Radioisotope gauges for industrial process measurements. Wiley, New York

Kanizawa FT, Ribatski G (2016) Two-phase flow patterns across triangular tube bundles for air-water upward flow. Int J Multiph Flow 80:43-56. https://doi.org/10.1016/j.ijmultiphaseflow.2015.11.004

Knoll GF (2000) Radiation detection and measurement, 3rd edn. Wiley, New York

Kowalczyk A, Hanus R, Szlachta A (2011) Investigation of the statistical method of time delay estimation based on conditional averaging of delayed signal. Metrol Meas Syst 17(2):335-342. https:// doi.org/10.2478/v10178-011-0015-3

Kozłowska M, Orlecka-Sikora B, Rudziński Ł, Cielesta S, Mutke G (2016) A typical evolution of seismicity patterns resulting from the coupled natural, human-induced and coseismic stresses in a longwall coal mining environment. Int J Rock Mech Mini Sci 86:5-15. https://doi.org/10.1016/j.ijrmms.2016.03.024

Krakowska P, Puskarczyk E (2015) Tight reservoir properties derived by nuclear magnetic resonance, mercury porosimetry and computed microtomography laboratory techniques Case study of Palaeozoic clastic rocks. Acta Geophys 63(3):789-814. https://doi. org/10.1515/acgeo-2015-0013

Kumara WAS, Halvorsen BM, Melaaen MC (2010) Single-beam gamma densitometry of oil-water flow in horizontal and slightly inclined pipes. Int J Multiph Flow 36:467-480. https://doi. org/10.1016/j.ijmultiphaseflow.2010.02.003

Kundu S, Kumbhakar M, Ghoshal K (2017) Reinvestigation on mixing length in an open channel turbulent flow. Acta Geophys. https:// doi.org/10.1007/s11600-017-0109-7

Morgado AO, Miranda JM, Araújo JDP, Campos JBLM (2016) Review on vertical gas-liquid slug flow. Int J Multiph Flow 85:348-368. https://doi.org/10.1016/j.ijmultiphaseflow.2016.07.002

Mosorov V (2006a) A method of transit time measurement using twin plane electrical tomography. Meas Sci Technol 17:753-760. https ://doi.org/10.1088/0957-0233/17/4/022/meta

Mosorov V (2006b) Phase spectrum method for time delay estimation using twin-plane electrical capacitance tomography. Electron Lett 42(11):630-632. https://doi.org/10.1049/iel:20060338

Mosorov V (2008) Flow pattern tracing for mass flow rate measurement in pneumatic conveying using twin plane electrical capacitance tomography. Part Part Syst Charact 25(3):259-265. https:// doi.org/10.1002/ppsc.200700034

Pietsch K, Marzec P, Kobylarski M, Danek T, Leśniak A, Tatarata A, Gruszczyk E (2007) Identification of seismic anomalies caused by gas saturation on the basis of theoretical $\mathrm{P}$ and PS wavefield in the Carpathian Foredeep, SE Poland. Acta Geophys 55(2):191-208. https://doi.org/10.2478/s11600-007-0002-x

Powell RL (2008) Experimental techniques for multiphase flows. Phys Fluids 20:040605. https://doi.org/10.1063/1.2911023

Rahim AR, Yunos MY, Rahiman MHF, Muji SZM, Thiam ChK, Rahim HA (2012) Optical tomography: velocity profile measurement using orthogonal and rectilinear arrangements. Flow Meas Instrum 23:49-55. https://doi.org/10.1016/j.flowmeasin st.2011.10.006

Roshani GH, Nazemi E (2017) Intelligent densitometry of petroleum products in stratified regime of two phase flows using gamma 
ray and neural network. Flow Meas Instrum 58:6-11. https://doi. org/10.1016/j.flowmeasinst.2017.09.007

Roshani GH, Nazemi E, Roshani MM (2017a) Application of radial basis function in densitometry of stratified regime of liquid-gas two phase flows. Radiat Meas 100:9-17. https://doi.org/10.1016/j. radmeas.2017.03.001

Roshani GH, Nazemi E, Roshani MM (2017b) Identification of flow regime and estimation of volume fraction independent of liquid phase density in gas-liquid two-phase flow. Prog Nucl Energy 98:29-37. https://doi.org/10.1016/j.pnucene.2017.02.004

Rząsa MR (2009) The measuring method for tests of horizontal twophase gas-liquid flows, using optical and capacitance tomography. Nucl Eng Des 239:699-707. https://doi.org/10.1016/j.nucen gdes.2008.12.020

Salgado CM, Pereira C, Schirru R, Brandão LEB (2010) Flow regime identification and volume fraction prediction in multiphase flows by means of gamma-ray attenuation and artificial neural networks. Prog Nucl Energy 52:555-562. https://doi.org/10.1016/j.pnuce ne.2010.02.001

Sommerlatt H-D, Andruszkiewicz A (2008) Dynamic measurement of particle diameter and drag coefficient using the ultrasonic method. Arch Acoust 33:351-362

Szabó NP, Dobróka M (2017) Robust estimation of reservoir shaliness by iteratively reweighted factor analysis. Geophysics 82(2):D69D83. https://doi.org/10.1190/geo2016-0393.1

Tamburini A, Cipollina A, Micale G, Brucato A (2013) Particle distribution in dilute solid liquid unbaffled tanks via a novel laser sheet and image analysis based technique. Chem Eng Sci 87:341-358. https://doi.org/10.1016/j.ces.2012.11.005

Vlasak P, Chara Z, Krupicka J, Konfrst J (2014) Experimental investigation of coarse particles-water mixture flow in horizontal and inclined pipes. J Hydrol Hydromech 62(3):241-247. https://doi. org/10.2478/johh-2014-00

Vlasak P, Chara Z, Konfrst J (2017) Flow behaviour and local concentration of coarse particles-water mixture in inclined pipes. J Hydrol Hydromech 65(2):183-191. https://doi.org/10.1515/ johh-2017-0001
Witczak S, Zuber A, Kmiecik E, Kania J, Szczepańska J, Różański K (2009) Tracer based study of the Badenian Bogucice Sands Aquifer, Poland. Nat Groundw Qual. https://doi.org/10.1002/97814 44300345.ch15

Xue T, Qu L, Cao Z, Zhang T (2012) Three-dimensional feature parameters measurement of bubbles in gas-liquid two-phase flow based on virtual stereo vision. Flow Meas Instrum 27:29-36. https://doi. org/10.1016/j.flowmeasinst.2012.07.007

Zeng X, Zhu Z, Chen Y (2016) Remote evaluation of rotational velocity using a quadrant photo-detector and a DSC algorithm. Sensors (Switzerland). https://doi.org/10.3390/s16050587

Zhao Y, Qincheng B, Richa H (2013) Recognition and measurement in the flow pattern and void fraction of gaseliquid two-phase flow in vertical upward pipes using the gamma densitometer. Appl Therm Eng 60:398-410. https://doi.org/10.1016/j.appltherma leng.2013.07.006

Zych M, Hanus R, Petryka L (2014) Application of spectral analysis in radiometric measurements of two-phase liquid-gas flow. MATEC Web Conf 18:02004. https://doi.org/10.1051/matecconf/20141 802004

Zych M, Hanus R, Petryka L, Świsulski D, Strzępowicz A, Zych P (2015) Application of gamma densitometry and statistical signal analysis to gas phase velocity measurements in pipeline hydrotransport. EPJ Web Conf 92:02122. https://doi.org/10.1051/epjco nf/20159202122

Zych M, Hanus R, Jaszczur M, Strzępowicz A, Petryka L, Mastej W (2016) Determination of void fraction in two phase liquid-gas flow using gamma absorption. JPCS 745:032124. https://doi. org/10.1088/1742-6596/745/3/032124

Zych M, Hanus R, Vlasák P, Jaszczur M, Petryka L (2017) Radiometric methods in the measurement of particle-laden flows. Powder Technol 318:491-500. https://doi.org/10.1016/j.powte c.2017.06.019

Zych M, Hanus R, Jaszczur M, Świsulski D, Petryka L, Jodłowski P, Zych P (2018) Evaluation of the structures size in the liquid-gas flow by gamma-ray absorption. EPJ Web Conf 180:02123. https ://doi.org/10.1051/epjconf/201818002123 